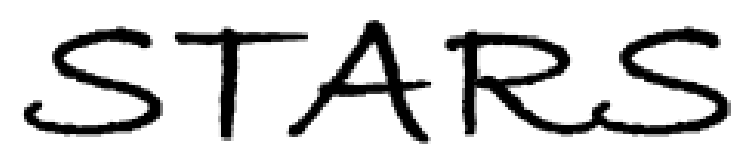

University of Central Florida

STARS

Retrospective Theses and Dissertations

1988

\title{
Uniform energy discharge for pulsed lasers
}

Eric Calvin Koschmann

University of Central Florida

Part of the Systems and Communications Commons

Find similar works at: https://stars.library.ucf.edu/rtd

University of Central Florida Libraries http://library.ucf.edu

This Masters Thesis (Open Access) is brought to you for free and open access by STARS. It has been accepted for inclusion in Retrospective Theses and Dissertations by an authorized administrator of STARS. For more information, please contact STARS@ucf.edu.

\section{STARS Citation}

Koschmann, Eric Calvin, "Uniform energy discharge for pulsed lasers" (1988). Retrospective Theses and Dissertations. 4301.

https://stars.library.ucf.edu/rtd/4301

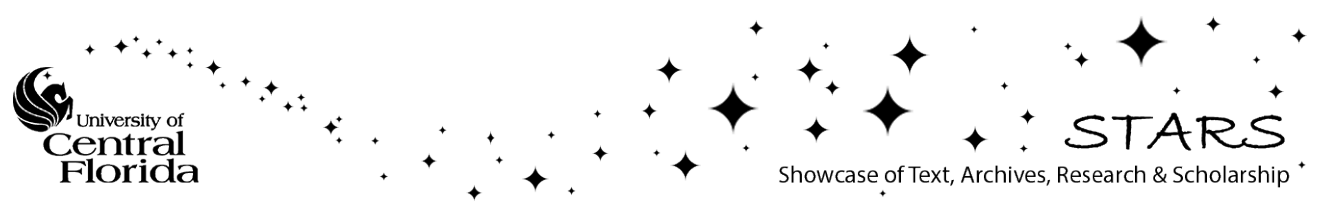




\author{
ERIC CALVIN KOSCHMANN \\ B.S.E.E., Valparaiso University, 1980
}

\title{
RESEARCH REPORT
}

Submitted in partial fulfillment of the requirements for the degree of Master of Science in Engineering in the Graduate Studies Program of the College of Engineering University of Central Florida orlando, Florida 


\section{ABSTRACT}

The art of achieving a large energy discharge in a controlled manner with relative ease is to use a pulse forming network. Historically the design of such networks generally used a single inductor and capacitor. Although easy to design and implement, this practice does not provide optimum performance in all cases. In particular, most laser welding requires a uniform energy discharge in a pulse to produce a high quality weld.

Analysis has shown that when the pulse forming network approximates a lumped constant transmission line a maximum flat pulse is produced with minimal degradation of the pulse rise time. This is highly favorable in achieving a producible design since all the capacitors will be of equal value as will all the inductors. This paper will show that a low pass filter ladder network composed of equal capacitors and inductors provides a flat pulse whose energy discharge becomes more uniform as the filter's order increases. 
TABLE OF CONTENTS

LIST OF TABLES • • • • • • • • • • • • iv

LIST OF FIGURES • • • • • • • • • • • • • • •

INTRODUCTION $•$ •

PULSE FORMING NETWORK REQUIREMENTS • • • . 2

Ideal Pulse Shape . . . . . . . .

The Transmission Line Approach . . . . 5

Practical PFN Circuit . . . . . . . 6

THE PFN OUTPUT PULSE TRANSFORM . . . . . . . 8

The Single-Mesh PFN . . . . . . . . 8

Double-Mesh PFN . . . . . . . . . 10

Nth-Mesh PFN . . . . . . . . . . 11

Nth PFN Equation Algorithm . . . . 14

SIMULATION OF THE PULSE FORMING NETWORK • • . 16

Single-Mesh Simulation . . . . . . 16

Multi-Mesh PFN Simulation . . . . . . 17

A 20-Mesh Simulation and Fourier Analysis 23

DESIGN PARAMETERS • • • • • • • • • • . 26

Design Intangibles . . . . . . . . 26

Flashlamp Characteristics . . . . . 27

PFN Component Calculations . . . . 28

Single-Mesh Circuit Values . . . . 29

Multi-Mesh Circuit Values . . . . 30

PFN DESIGN EXAMPLE • • • • • • • • • • 35

CONCLUDING REMARKS • • • • • • • • • • 43

APPENDIX • . • . . . • • • • • • • • 44

REFERENCES • • • • • • • • • • • • 51 


\section{LIST OF TABLES}

1. The Coefficients for the Nth PFN output Transform Function 
1. Ideal Rectangular Pulse . . . . . . 3

2. a) $A \sin (\pi \mathrm{fT}) / \pi \mathrm{f} \quad$. $\quad . \quad . \quad . \quad . \quad . \quad 44$

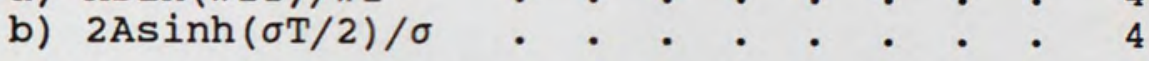

3. Pulse Forming Network Configuration . . 6

4. Single-Mesh Pulse Forming Network . . 8

5. Load Current from a Single-Mesh PFN . . 10

6. The Double-Mesh PFN Circuit . . . . 11

7. Two Port Network . . . . . . . . . 12

8. Single-Mesh Critically Damped Load Current 17

9. Dual-Mesh PFN Output Pulse • • . . 18

10. Output Pulse Shape for a 3-Mesh PFN . . 19

11. Output Pulse Shape for a 4-Mesh PFN . . 19

12. Output Pulse Shape for a 5-Mesh PFN . . 20

13. Output Pulse Shape for a 6-Mesh PFN . . 20

14. Output Pulse Shape for a 7-Mesh PFN . . 21

15. Output Pulse Shape for a 8-Mesh PFN . . 21

16. Output Pulse Shape for a 9-Mesh PFN • . 22

17. Output Pulse Shape for a 10-Mesh PFN . . 22

18. Output Pulse Shape of a 20-Mesh PFN Delayed 8 Seconds . . . . . . . . 24

19. Fourier Analysis for the Output Pulse of the 20-Mesh PFN . . . . . . . 25

20. PFN Construction of an Industrial Laser . 36

21. PFN Circuit of an Industrial Laser . . . 37 
22. Present PFN Configuration Discharge Current and Power Simulation . . . . 38

23. Discharge Current Into the Flashlamps . . 39

24. Resulting Laser Optical Output Pulse . 39

25. Simulation Results for the New PFN . . 41

26. The New PFN Design Output Current Pulse • 42

27. The New PFN Design Output Optical Pulse • 42 


\section{INTRODUCTION}

A controlled energy discharge is often required for driving various non-linear loads such as flashlamps, heart defibrilators, and ignition systems. Generally a single capacitor and inductor tank circuit will suffice, and the design of this is well documented. When the pulse shape of the discharge is required to be rectangular, then a simple capacitor and inductor circuit will no longer provide satisfactory performance.

Multiple mesh pulse forming networks are then required to generate longer pulses with rectangular shapes. This report will show how a low pass ladder LC network can approximate a lumped constant transmission line to produce the desired transient pulse. The design and component value computation for a multiple mesh pulse forming network used to drive a krypton flashlamp in a pulsed Nd:YAG laser for welding thin metals will be developed. 


\section{PULSE FORMING NETWORK REQUIREMENTS}

The goal of pulse forming networks is not just to generate an output of the desired shape, but to allow a discharge of energy in a controlled manner so that useful work can be done. There are many applications, especially in the laser related fields, that require a burst of energy in a short period of time to yield a very high peak power while the average power is kept to a minimum. This is where the pulse forming network, or PFN, comes in.

The PFN will store energy over a long period so as to keep the average power low. When enough energy has been stored, the PFN will "dump" this energy very abruptly into the load thus producing for a short period of time very high peak powers. This is extremely useful in such laser applications as hole drilling, rangefinding, cutting, and welding. This is also what makes a defibrilator restart a heart, and an ignition system run an internal combustion engine.

Each of these applications has different requirements for its pulse forming network. In general, the amount of energy and the pulse width are the two predominant features. Satisfying these two requirements alone will usually suffice, except when it comes to laser welding. In laser welding the pulse shape is critical. The proper 
shape will yield a clean and uniform weld, while a poor shape can cause a weld with pits or excessive heating of the material.

\section{Ideal Pulse Shape}

For laser welding the optimum performance is achieved with a rectangular pulse that is maximally flat. Other uses of PFNs may require a different pulse shape, but this report will concentrate on generating the rectangular pulse.

The ideal rectangular pulse $i(t)$ is zero for all time before $t=-T / 2$. At $t=-T / 2$ there is an instantaneous change to a high level of amplitude $A$. The signal remains at amplitude $\mathrm{A}$ until time $\mathrm{T}$ seconds later when it instantaneously changes back to the zero level and stays there until infinity. This is represented in Figure 1.

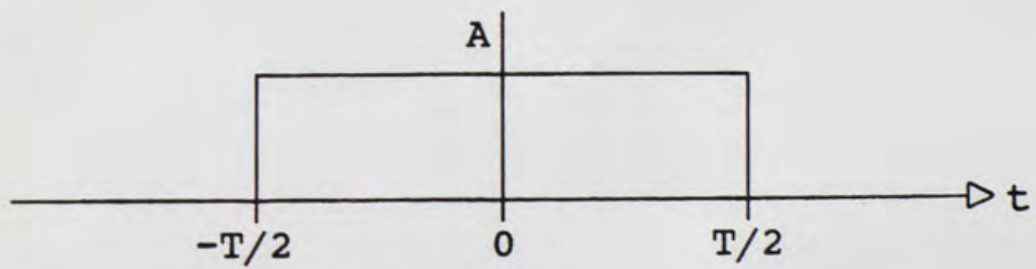

Figure 1. Ideal Rectangular Pulse.

This pulse can be thought of as composed of two unit step functions. One unit step function turns on the pulse, and the other unit step function turns off the pulse. This is written as 


$$
i(t)=A[u(t+T / 2)-u(t-T / 2)] \text { amps. }
$$

Taking the Laplace transform of each side yields:

$$
L\{i(t)\}=A\left[e^{s T / 2}-e^{-s T / 2}\right] / s
$$

When $s$ is equal to $j 2 \pi \mathrm{f}$ this can be reduced to the familiar Fourier transform for the rectangular pulse

$$
F\{i(t)\}=A \sin (\pi f T) / \pi f
$$

And conversely, when $s$ is equal to the real number $\sigma$, then equation 2 reduces to

$$
L\{i(t)\}=2 A \sinh (\sigma T / 2) / \sigma
$$

These two equations show that the pulse forming network will have to have equally spaced zeros that lie on the imaginary $(j 2 \pi f)$ axis, with a pole at infinity on the real $(\sigma)$ axis. This can be seen from Figure $2 \mathrm{a}$ and $2 \mathrm{~b}$ of the $\sin x / x$ and $\sinh x / x$ curve shapes.
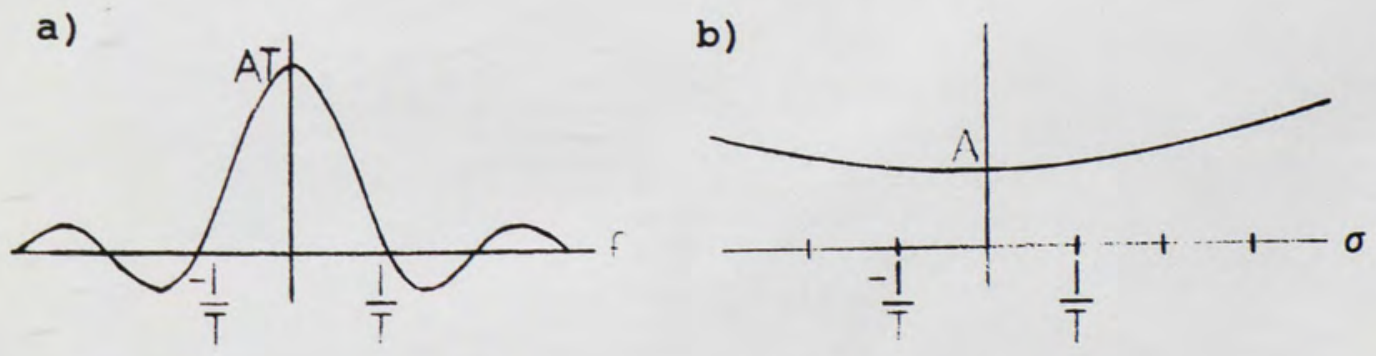

Figure 2. a) $A \sin (\pi f T) / \pi f$

b) $2 \mathrm{Asinh}(\sigma \mathrm{T} / 2) / \sigma$. 


\section{The Transmission Line Approach}

The circuit that generates the optimum pulse is a charged open ended transmission line switched into a matched load (Koechner 1976, 292). The current in a transmission line at any point is defined as

$$
I_{X}=\left(I_{0}{ }^{+}\right)\left(e^{\tau X}\right)+\left(I_{0}{ }^{-}\right)\left(e^{-\tau X}\right) \text { amps }
$$

where $\mathrm{I}_{0}{ }^{+}$and $\mathrm{I}_{0}{ }^{-}$are the incident and the reflected load currents, respectively, and $I_{x}$ is the current a distance $x$ away from the end. The propagation constant $\tau$ is defined as

$$
\tau=[(r+j 2 \pi f l)(g+j 2 \pi f c)]^{1 / 2}
$$

(Albrecht 1977, sec. 8-3).

If the end of the line is left open, then all of the incident energy is reflected and $\mathrm{I}_{0}{ }^{+}=-\mathrm{I}_{0}{ }^{-}$(Albrecht 1977, sec. $8-8)$. The current is related to the voltage by the impedance of the line such that $\mathrm{I}_{0}{ }^{+}=\mathrm{V}_{0}{ }^{+} / \mathrm{Z}_{0}$. Now by putting a matched impedance load at the other end of the line, the load current will look like

$$
I_{r}=V_{0}^{+}\left(e^{j 2 \pi f D(l c)^{1 / 2}}-e^{-j 2 \pi f D(l c)^{1 / 2}}\right) / z_{o} \text { amps, }
$$

where $\mathrm{D}$ is the total length of the transmission line. 
Since the transmission line was initially charged to $v_{i}$, then $v_{0}{ }^{+}$is equal to $v_{i} / j \pi f$. Now this takes on the form of equation (3) above, where $T=2 D(1 c)^{1 / 2}$ and $\mathrm{A}=\mathrm{V}_{\mathrm{i}}{ }^{+} / 2 \mathrm{z}_{0}$.

Unfortunately a transmission line is not a very practical PFN; therefore, a lumped constant network is used as an approximation to the transmission line.

\section{Practical PFN Circuit}

The circuit configuration that is generally used is the capacitor and inductor ladder network as shown in Figure 3. This network approximates the performance of the transmission line with just a few meshes, that is, capacitor and inductor cells.

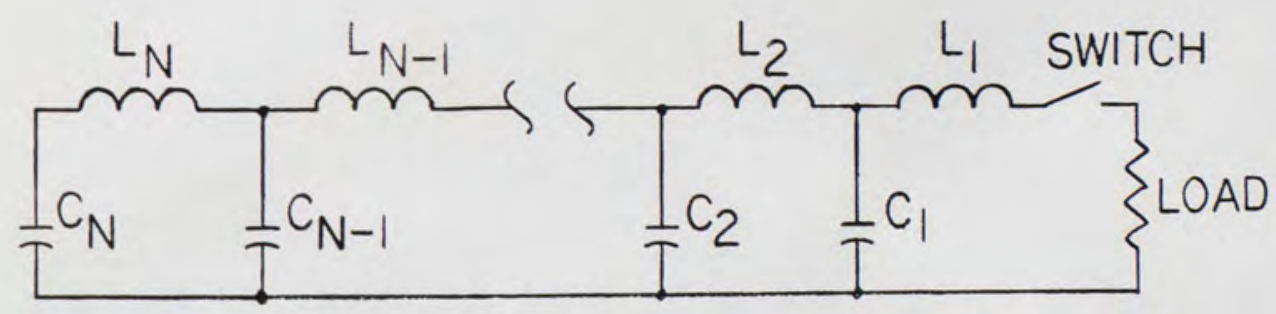

Figure 3. Pulse Forming Network Configuration.

The capacitor is the energy storage device, while the inductor helps control the pulse width. The inductor can be used as the energy storage component, and usually is in the ignition applications. Due to physical and practical restraints, the inductor's use as the energy storage device is normally limited to under a few millijoules. 
The switch of the pulse forming network controls when the "dump" takes place. This device can be a high powered semiconductor, a relay, a thyraton, a spark gap, or other high current device.

The load that the PFN must work into is almost always complex and non-linear. Because of this the load's characteristics around the desired operating point are approximated to be linear. The initial analysis and modeling will use a simple resistive load. Later a first order approximation to a Krypton gas filled flashlamp will be used in a Microcap circuit simulation and compared to the actual performance. 
In the following section the derivation of the output load current Laplace transform is generated. This is done for the simplest single-mesh circuit first followed by the double-mesh. Then a generalized form is established for the nth-mesh network along with an algorithm to generate the equations.

\section{The Single-Mesh PFN}

The simplest and most often used PFN is a single-mesh circuit as shown in Figure 4. The capacitor is charged up to its initial voltage $\mathrm{v}_{i}$, and the amount of energy stored is given by:

$$
\mathrm{E}=\mathrm{CV}_{\mathrm{i}}^{2} / 2 \text { joules. }
$$

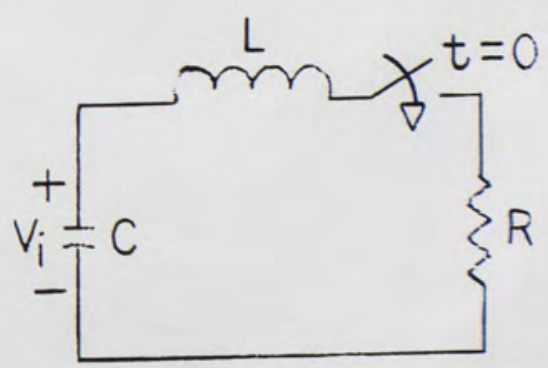

Figure 4. Single-Mesh Pulse Forming Network.

For this simple case the currents summed at any node are the same for the other nodes, that is: 


$$
I_{C}=I_{l}=I_{r} \text { amps. }
$$

The currents are initially all zero since the switch is open. At time $t=0$ the switch will close and current will begin to flow. Now summing the voltages around the loop yields:

$$
\mathrm{v}_{\mathrm{c}}=\mathrm{v}_{1}+\mathrm{v}_{\mathrm{r}} \text { volts. }
$$

Since the interest is in the load current, the above equation can be rewritten using $I_{r}$ and $v_{i}$ getting

$$
\frac{\mathrm{v}_{i}}{\mathrm{~s}} \frac{-\mathrm{I}_{\mathrm{r}}}{\mathrm{sC}}=\mathrm{SLI} \mathrm{I}_{\mathrm{r}}+\mathrm{RI} \mathrm{I}_{\mathrm{r}}
$$

Finally solving for $I_{r}$ yields:

$$
I_{r}=\frac{v_{i} C}{s^{2} L C+s R C+1}
$$

This is the classic RLC response (Barna 1970, 30).

For optimum performance the current needs to be critically damped, which means that $R=2(L / C)^{1 / 2}$. This solution dumps the energy into the load the quickest and without any ringing. Ringing in the output should be avoided; otherwise severe damage can result to the load and to the capacitors of the network. The capacitors for this type of work are often rated for $10 \%$ to $20 \%$ voltage reversal; more than this can ruin a capacitor very quickly. Worst of all the capacitor could explode. 
As one can see, this output form has no zeros and just two poles. Then it is not expected to have the rectangular shape that is desired. In fact, this case is the only one in which an equation in the time domain can be easily found from the output's transform. Since the interest is in the critically damped case the output becomes

$$
i_{r}(t)=V_{i} t\left(e^{-t R / 2 L}\right) / L \text { amps. }
$$

From this we can find the peak current value and the $50 \%$ points. Here is a good spot to define the network impedance $z_{0}=(L / C)^{1 / 2}$, which is the same as the transmission line impedance. Then the peak current becomes $i_{\mathrm{p}}=\mathrm{Vi} / \mathrm{z}_{\mathrm{o}} \mathrm{e}$, and the pulse width measured at the $50 \%$ points is $\mathrm{PW} \approx 2.5(\mathrm{LC})^{1 / 2}$ as shown in Figure 5 .

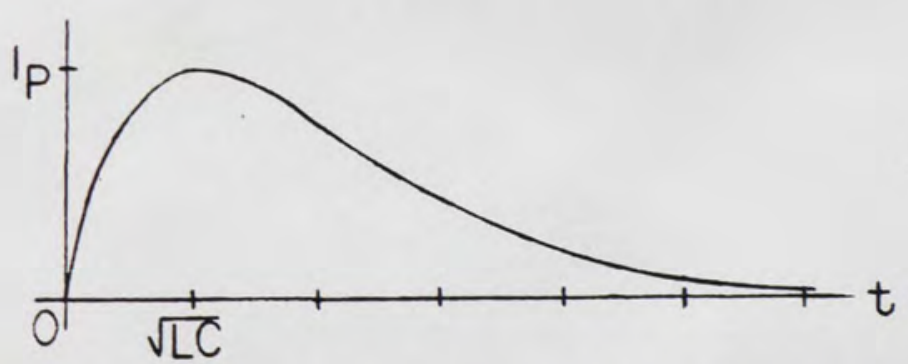

Figure 5. Load Current from a Single-Mesh PFN.

\section{Double-Mesh PFN}

Now consider the double-mesh network. There are some more equations to work through to get to the output load 
current. Looking at Figure 6 helps one to get started by summing the voltages around the two loops:

$$
s L I_{r}+R I_{r}+\frac{\left(I_{r}-I_{1}\right)}{s C}-\frac{V_{i}}{s}=0
$$

for loop 1 and for loop 2 yields

$$
s L I_{1}-\frac{\left(I_{r}-I_{1}\right)}{s C}+\frac{V_{i}}{s}+\frac{I_{1}}{s C}-\frac{V_{i}}{s}=0
$$

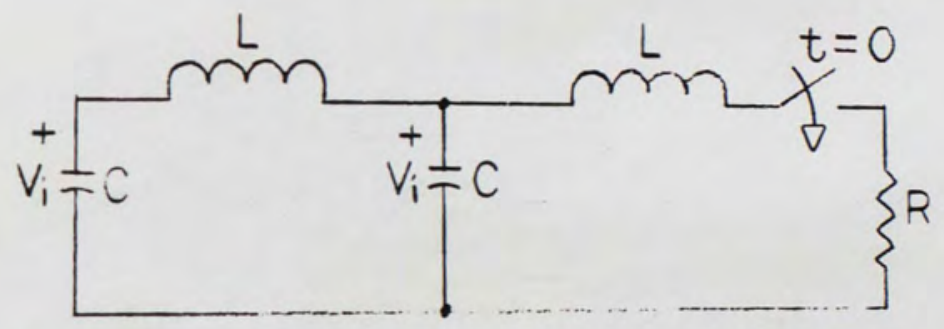

Figure 6. The Double-Mesh PFN Circuit.

Solving equation (15) for $I_{1}$, substituting it into the first equation, and then solving for $I_{r}$ will lead to:

$$
I_{r}=\frac{v_{i} C\left(s^{2} L C+2\right)}{s^{4}(L C)^{2}+s^{3} R C L C+3 s^{2} L C+2 s R C+1} .
$$

Notice the zeros at $s= \pm j(2 / L C)^{1 / 2}$.

\section{Nth-Mesh PFN}

For larger mesh PFNs the equations become very difficult to work with; therefore, the two port network matrix analysis method will be used. 
For every network that has an input and output port as shown in Figure 7, that network can be totally defined by a matrix where

$$
\left[\begin{array}{l}
V_{1} \\
I_{1}
\end{array}\right]=\left[\begin{array}{ll}
A_{11} & A_{12} \\
A_{21} & A_{22}
\end{array}\right]\left[\begin{array}{l}
V_{2} \\
I_{2}
\end{array}\right] .
$$

(Brown et al. 1973, 109)

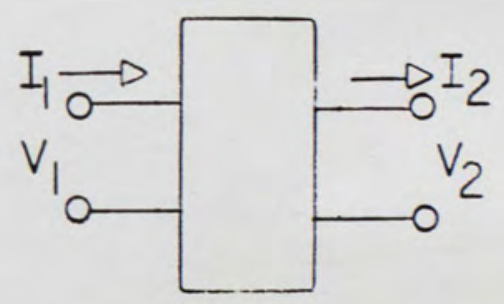

Figure 7. Two Port Network.

For the single inductor and capacitor network that matrix is

$$
\left[\begin{array}{cc}
1 & s L \\
s C & s^{2} L C+1
\end{array}\right] \text {. }
$$

Comparing the matrix parameters with the equation for the output load current found earlier, it is noticed that:

$$
I_{r}=\frac{V_{i}}{s} * \frac{A_{21}}{A_{21} R+A_{22}} .
$$

Having noticed this similarity, then one can easily find the output equations for any mesh PFN. All that has 
to be done is to multiply the above matrix for the single LC case with itself $n$ times for an $n^{\text {th }}$-mesh PFN. In this way the next level mesh circuit matrix can be defined easily as

$$
\left[\begin{array}{ll}
\mathrm{B}_{11} & \mathrm{~B}_{12} \\
\mathrm{~B}_{21} & \mathrm{~B}_{22}
\end{array}\right]=\left[\begin{array}{ll}
\mathrm{A}_{11} & \mathrm{~A}_{12} \\
\mathrm{~A}_{21} & \mathrm{~A}_{22}
\end{array}\right] *\left[\begin{array}{cc}
1 & \mathrm{sL} \\
\mathrm{sC} & \mathrm{s}^{2} \mathrm{LC}+1
\end{array}\right] .
$$

Where the $\mathrm{A}$ matrix is for the $\mathrm{n}^{\text {th }}$-mesh and the $\mathrm{B}$ matrix is for the $n+1$ mesh PFN.

Since the output contained only the second row's parameters, then all that is needed is to calculate the $\mathrm{B}_{21}$ and $\mathrm{B}_{22}$ portions of the matrix. Multiplying rows by columns produces

$$
\mathrm{B}_{21}=\mathrm{A}_{21}+\mathrm{sCA} 22
$$

and

$$
B_{22}=s L A_{21}+\left(s^{2} L C+1\right) A_{22} .
$$

Then for the dual-mesh pulse forming network $\mathrm{B}_{21}=\mathrm{sC}+\mathrm{sC}\left(\mathrm{s}^{2} \mathrm{LC}+1\right)=\mathrm{s}^{3} \mathrm{LC} \mathrm{C}^{2}+2 \mathrm{sC}$, and $B_{22}=s L s C+\left(s^{2} L C+1\right)\left(s^{2} L C+1\right)=s^{4} L^{2} c^{2}+3 s^{2} L C+1$. After plugging these parameters into the equation for $I_{r}$, the result is the output equation for the dual-mesh PFN that was generated earlier. 
The $\mathrm{A}_{21}$ and $\mathrm{B}_{21}$ parameters contain only the odd orders of $\mathrm{s}$, while the $\mathrm{A}_{22}$ and $\mathrm{B}_{22}$ parameters contain only the even orders of $\mathrm{s}$. Then the $\mathrm{A}_{21}$ and $\mathrm{A}_{22}$ parameters can be written in a more generic form for the nth-mesh PFN as:

$$
\begin{aligned}
& A_{21}=s^{2 n-1} C(L C)^{n-1}+a_{n}{ }^{2 n-3} s^{2 n-3} C(L C)^{n-2}+\ldots+a_{n}{ }^{1} s C \\
& A_{22}=s^{2 n}(L C)^{n}+a_{n}{ }^{2 n-2} s^{2 n-2}(L C)^{n-1}+\ldots+a_{n}{ }^{2} s^{2} L C+1
\end{aligned}
$$

where the coefficient for the $s^{\mathrm{m}}$ component and the nth PFN is denoted by $a_{n} m$.

\section{Nth PFN Equation Algorithm}

Since the nth PFN's matrix $A_{21}$ and $A_{22}$ parameters are related to the $n+1$ PFN's matrix parameters by the $B_{21}$ and $B_{22}$ equations, then the $a_{n+1}{ }^{m}$ coefficients can be easily computed from the $a_{n} m$ coefficients from the previous parameters. Thus, the following algorithm will generate the coefficients for the $n+1$ PFN, where

$$
a_{n+1} m_{n} a_{n} m_{n} a^{m-1} \text {, }
$$

for odd values of $\mathrm{m}$, and

$$
a_{n+1}{ }^{m}=a_{n}{ }^{m}+a_{n}{ }^{m-1}+a_{n}{ }^{m-2} \text { or } a_{n+1}{ }^{m}=a_{n}{ }^{m}+a_{n+1}{ }^{m-1} \text {, }
$$

for even values of $\mathrm{m}$.

A simple basic program was written on a TI 99/4A home computer to generate the coefficients of up to a 20 th-mesh PFN. The output and program listing are in the appendix. 
The coefficients generated by this algorithm for up to the 8th-mesh are listed in Table 1.

\section{TABLE 1}

THE COEFFICIENTS FOR THE NTH PFN OUTPUT TRANSFORM FUNCTION.

\begin{tabular}{|c|c|c|c|c|c|c|c|c|c|c|c|c|c|c|c|c|c|c|c|c|}
\hline \multicolumn{8}{|c|}{$\begin{array}{llllll}m=16 & 15 & 14 & 13 & 12 & 11\end{array}$} & 10 & 9 & & 8 & 7 & 6 & 5 & $\underline{4}$ & & 3 & 2 & 10 & \\
\hline \multicolumn{21}{|c|}{$\mathrm{n}$} \\
\hline 1 & & & & & & & & & & & & & & & & & & & & \\
\hline 2 & & & & & & & & & & & & & & & 1 & & 1 & 3 & & \\
\hline 3 & & & & & & & & & & & & & 1 & 1 & 5 & & 4 & 6 & 3 & 1 \\
\hline 4 & & & & & & & & & & & 1 & 1 & 7 & 6 & 15 & 51 & 0 & 10 & 4 & 1 \\
\hline 5 & & & & & & & & 1 & 1 & & 9 & 8 & 28 & 21 & 35 & 52 & 0 & 15 & 5 & 1 \\
\hline 6 & & & & & 1 & 1 & 1 & 11 & 10 & & 45 & 36 & 84 & 56 & 70 & 3 & 5 & 21 & 6 & 1 \\
\hline 7 & & & 1 & 1 & 13 & 12 & & 66 & 55 & & 65 & 120 & 210 & 126 & 126 & & 6 & 28 & 7 & 1 \\
\hline 8 & 1 & $11:$ & 5 & 14 & 91 & 78 & & 286 & 220 & & & 330 & 462 & 252 & 210 & & & 36 & & \\
\hline
\end{tabular}

Now by using the coefficients generated by the algorithm and the general forms for $A_{21}$ and $A_{22}$, the transform for the output pulse for any size PFN can easily be written. For example, the 4 th-mesh PFN output equation becomes:

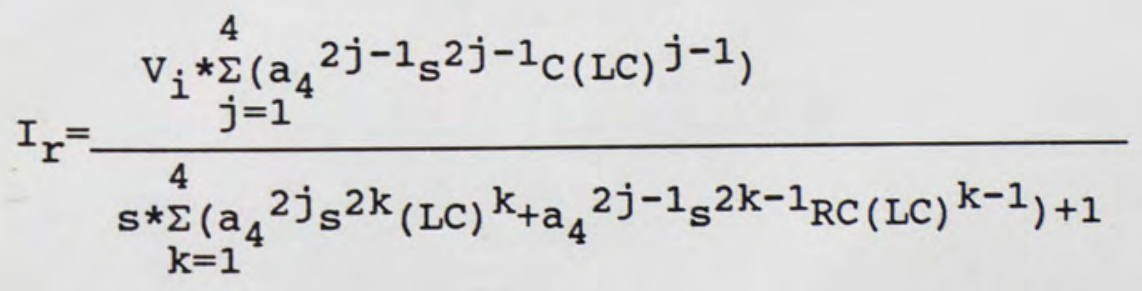

finally

$$
\begin{gathered}
I_{r}=\frac{v_{i} C\left(s^{6}(L C)^{3}+6 s^{4}(L C)^{2}+10 s^{2} L C+4\right)}{s^{8}(L C)^{4}+s^{7} R C(L C)^{3}+7 s^{6}(L C)^{3}+6 s^{5} R C(L C)^{2}} \\
+15 s^{4}(L C)^{2}+10 s^{3} R C L C+10 s^{2} L C+4 s R C+1
\end{gathered} .
$$




\section{SIMULATION OF THE PULSE FORMING NETWORK}

Circuit simulation of pulse forming networks can be done either by scaling the circuit down into small usable components, or by using a circuit simulator on a personal computer. Many PFNs use either very large capacitors and inductors, or high voltages (which are extremely dangerous to work with), or both. Because of this it is very important to use simulation to verify proper operation of a proposed PFN before building it.

In this section of the report a PFN model will be normalized and simulated to verify the output pulse shape for different levels of PFNs. A transient analysis will be run using Microcap II to show the output pulse shape.

\section{Single-Mesh Simulation}

The first case will be the simple critically damped single-mesh pulse forming network. For this normalized circuit the capacitor and inductor are equal to one, while the load resistor is equal to two according to the earlier requirement for being critically damped.

The use of Microcap II on a personal computer makes the simulation very easy to do. A switch is not necessary because the transient analysis of Microcap allows the user to generate initial conditions. Once the initial 
conditions are set, the simulation then shows the resulting output due to those conditions.

For this case the total time was set for five seconds, and the capacitor's initial voltage was set to one volt. The resulting output is shown in Figure 8 . The peak current turns out to be 0.368 amps with the pulse width being 2.5 seconds at the $50 \%$ points. This is just what is expected.

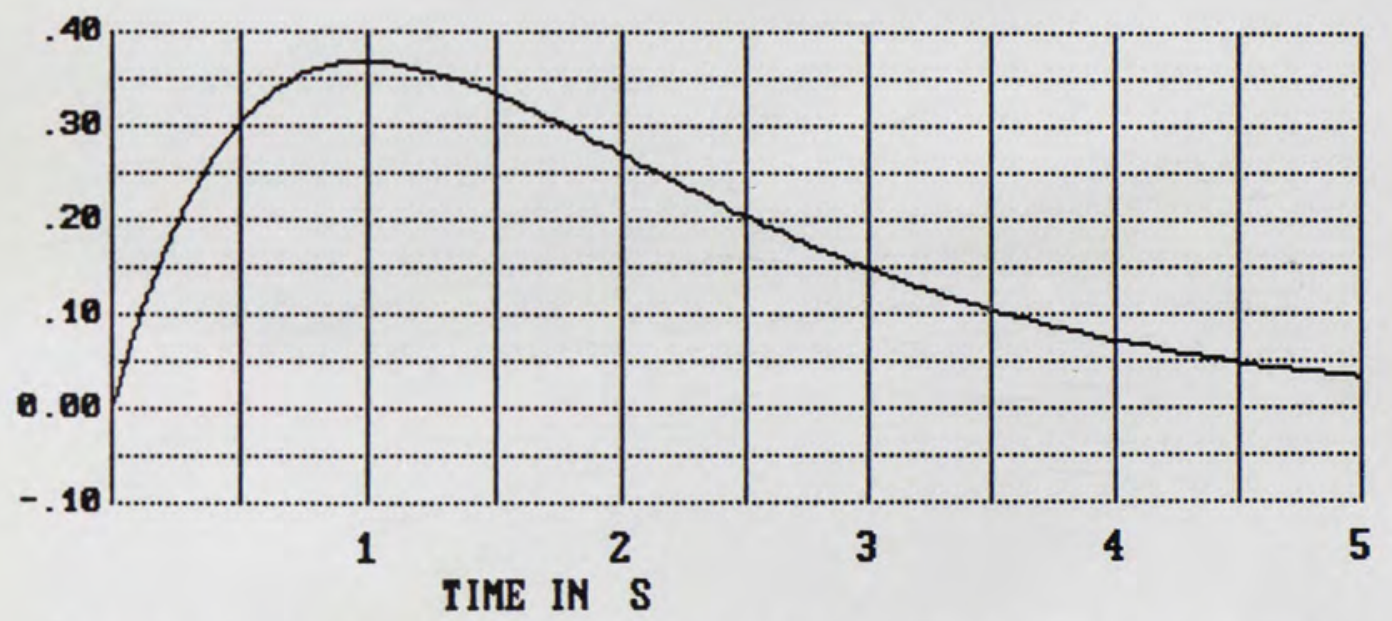

Figure 8. Single-Mesh Critically Damped Load Current.

\section{Multi-Mesh PFN Simulation}

The modeling of the multi-mesh circuit is very similar to the single-mesh case, except that the ladder network now approximates the lumped constant transmission line. Since a transmission line needs to be terminated in a load impedance that matches the network impedance $\mathrm{z}_{0}$, the load resistance is one ohm for the following normalized cases. 
The total capacitance and inductance of each network is the same as in the single-mesh case. In this manner, each network is delivering the same amount of energy to the load. The individual capacitance and inductance values for these normalized cases turns out to be $c=1 / n$ and $\mathrm{L}=1 / \mathrm{n}$, where $\mathrm{n}$ is the mesh number.

Figure 9 shows the expected output from a dual-mesh normalized network. This pulse begins to have the desired rectangular shape. Just the addition of one capacitor and one inductor makes a big difference in the pulse shape when compared to the single-mesh case.

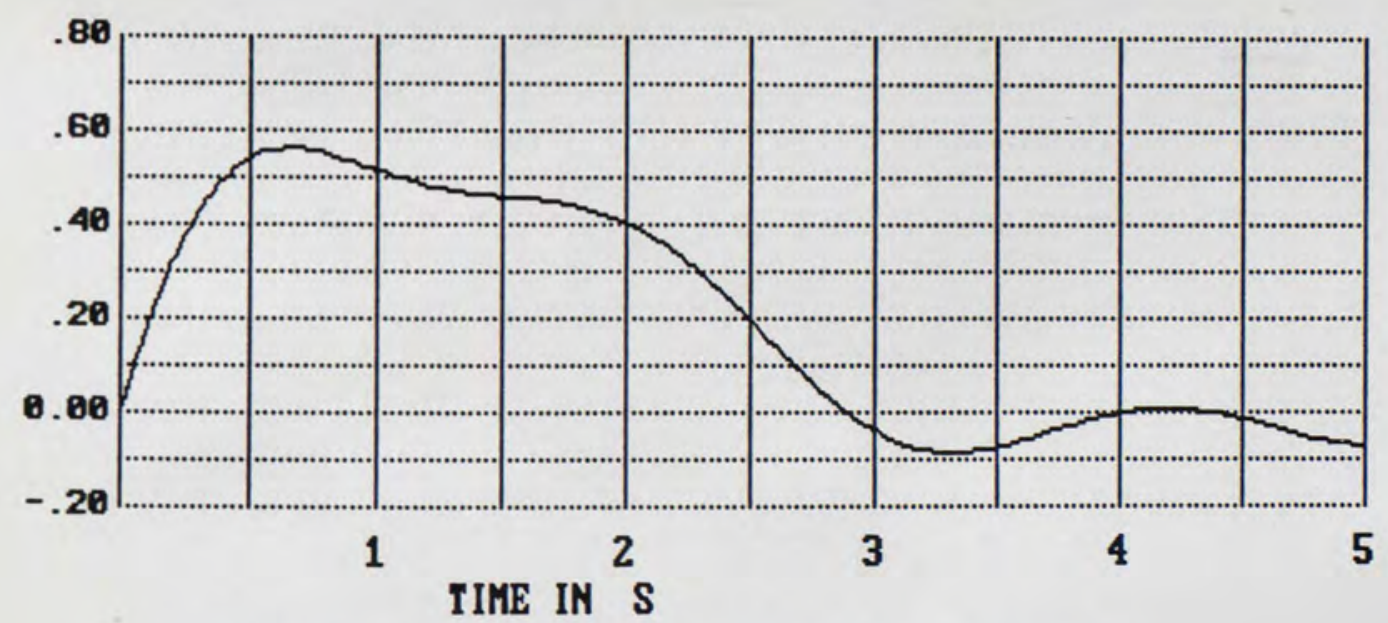

Figure 9. Dual-Mesh PFN Output Pulse.

The following figures numbered 10 through 17 show the outputs for a three-mesh network through to a ten-mesh network. In each of these successive figures the rectangular shape of the pulse becomes more obvious; also the rise time of the pulse becomes shorter. 


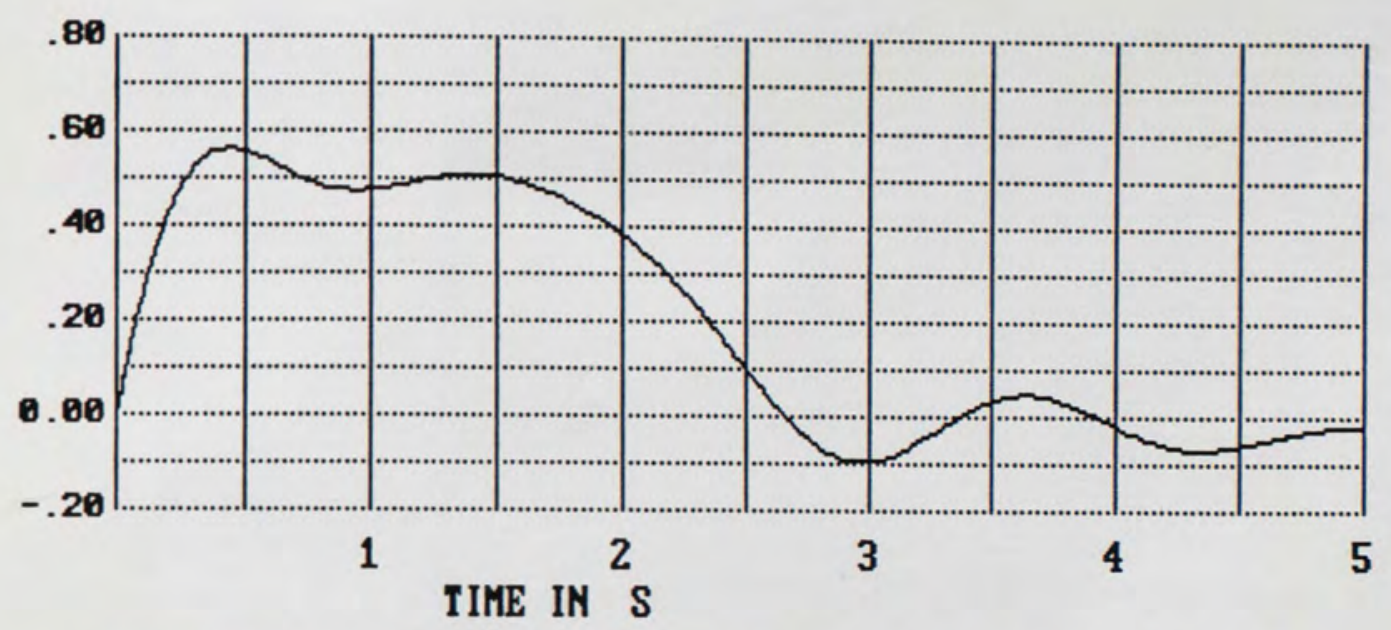

Figure 10. Output Pulse Shape for a 3-Mesh PFN.

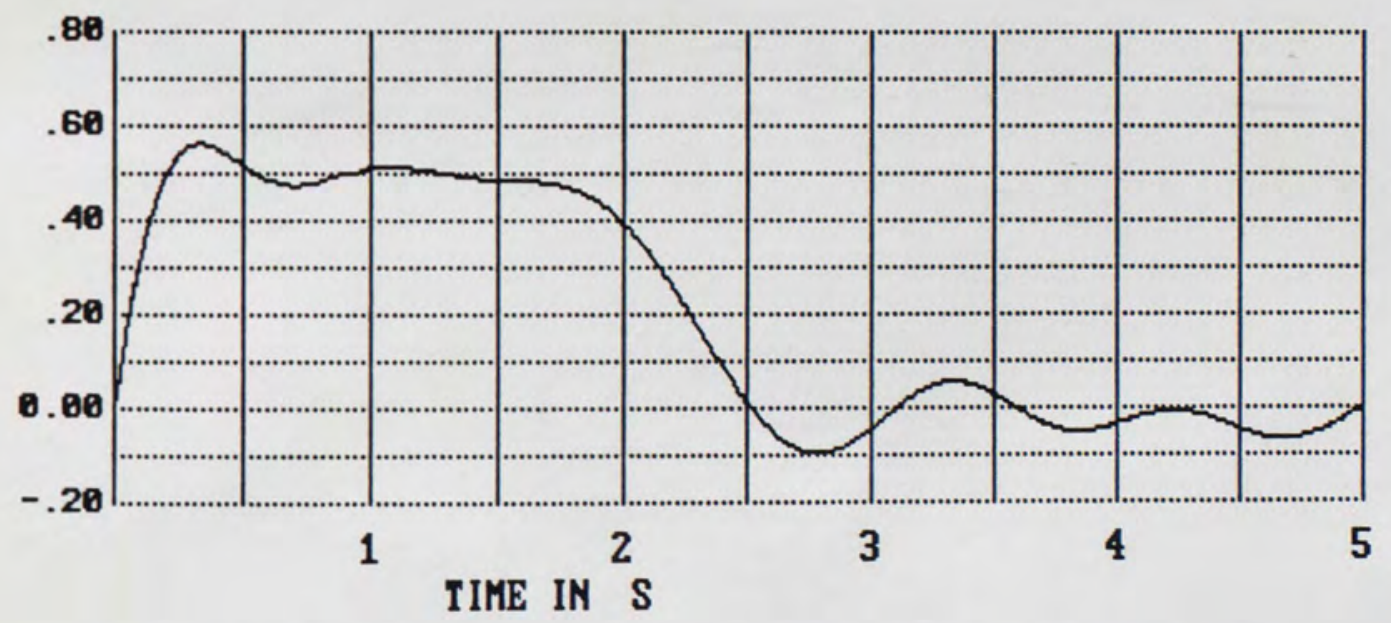

Figure 11. Output Pulse Shape for a 4-Mesh PFN. 


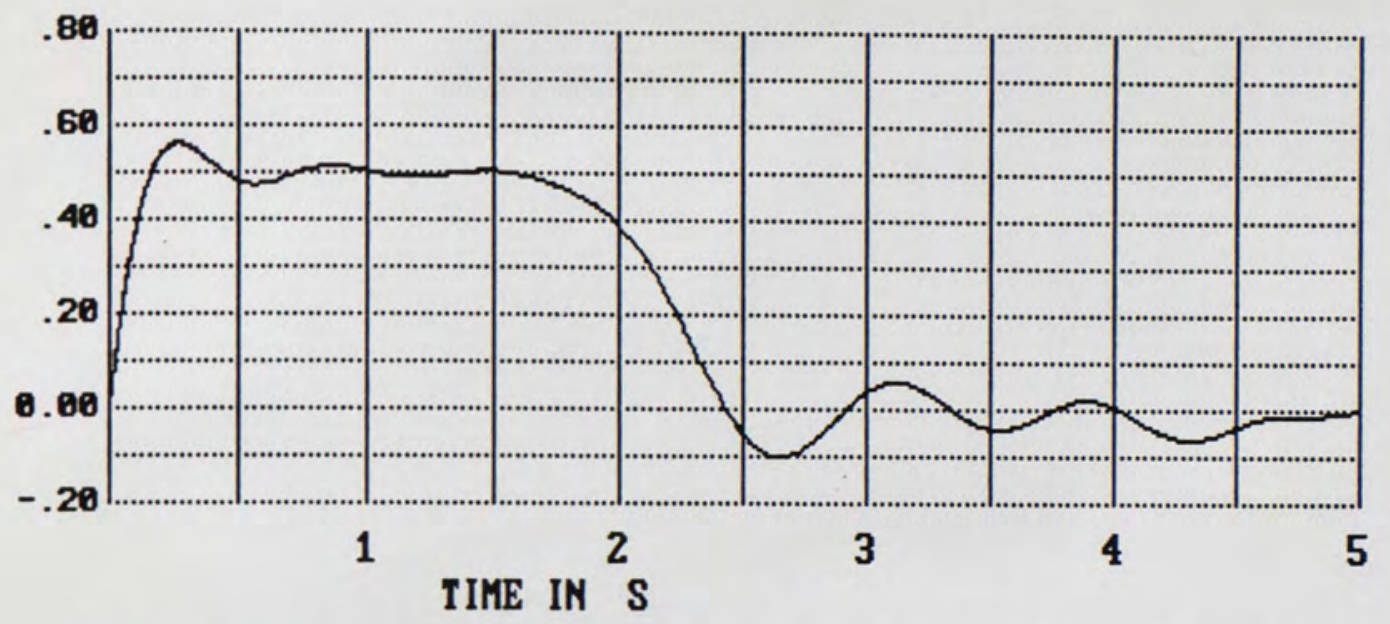

Figure 12. Output Pulse Shape for a 5-Mesh PFN.

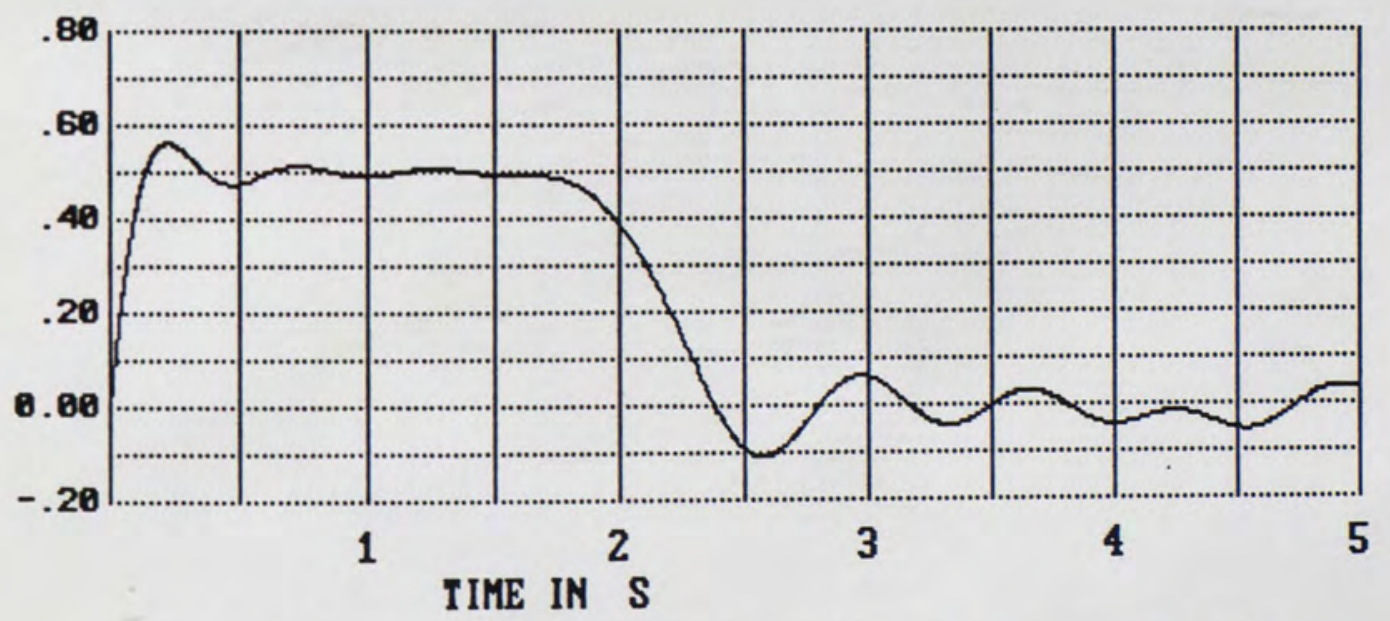

Figure 13. Output Pulse Shape for a 6-Mesh PFN. 


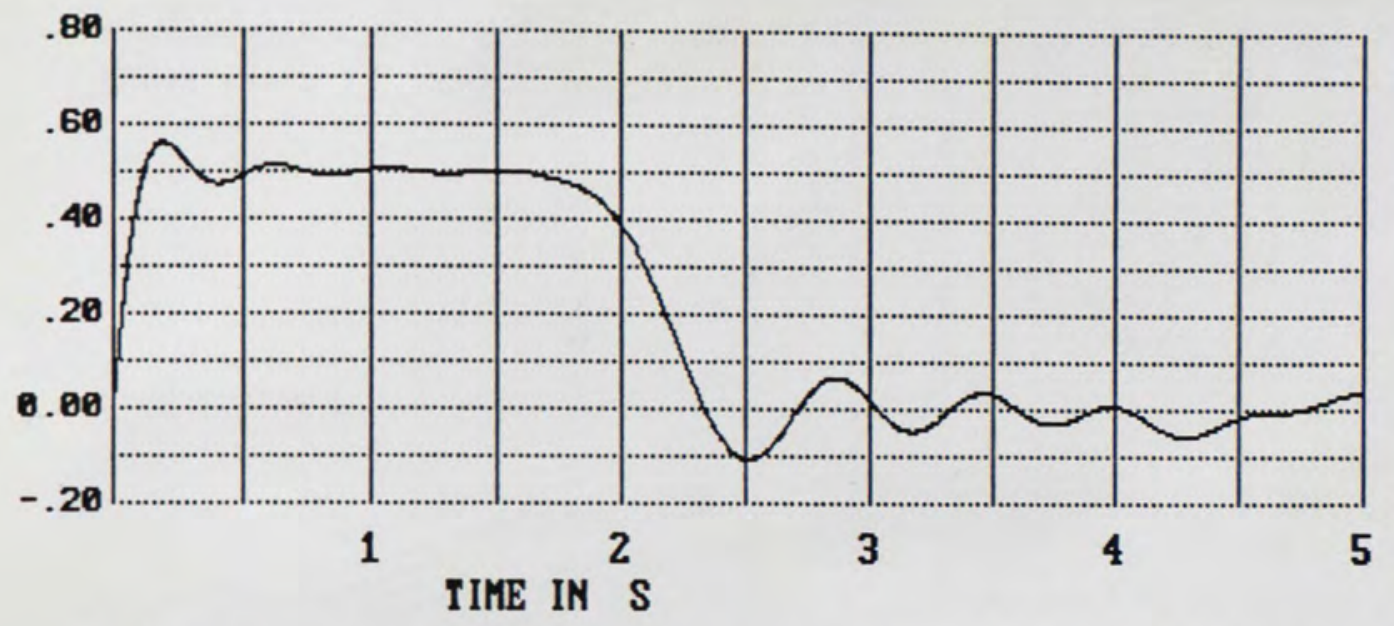

Figure 14. Output Pulse Shape for a 7-Mesh PFN.

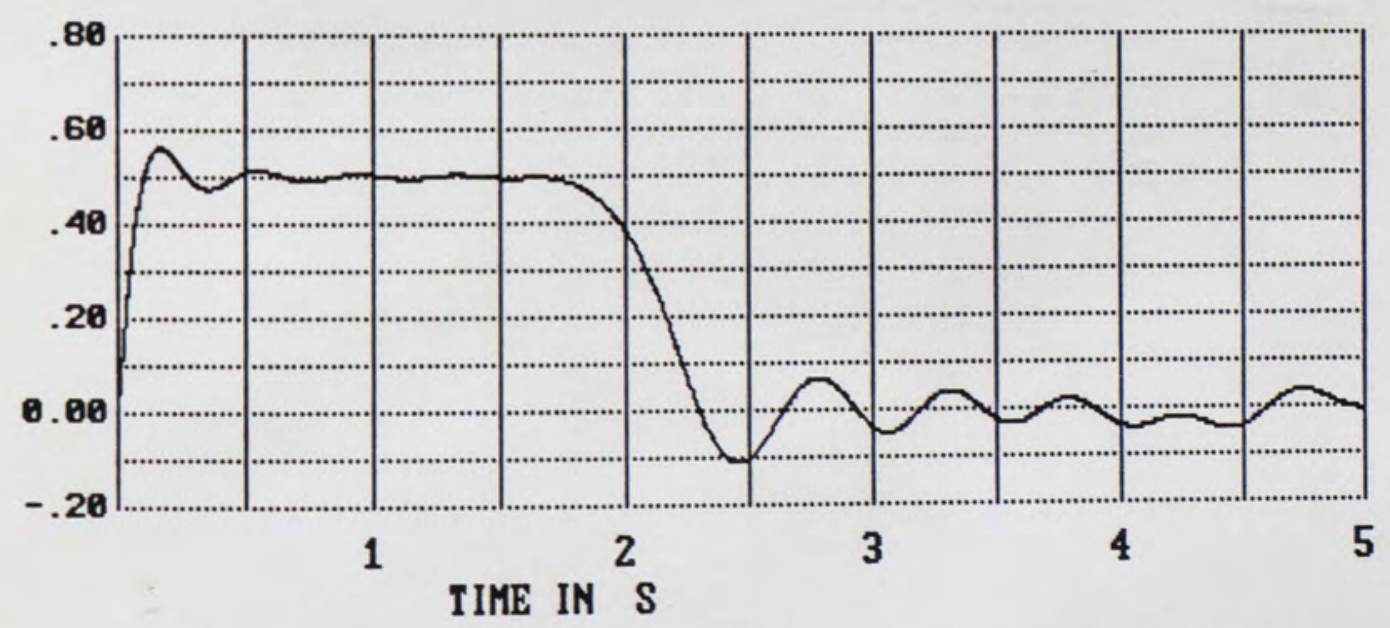

Figure 15. Output Pulse Shape for a 8-Mesh PFN. 


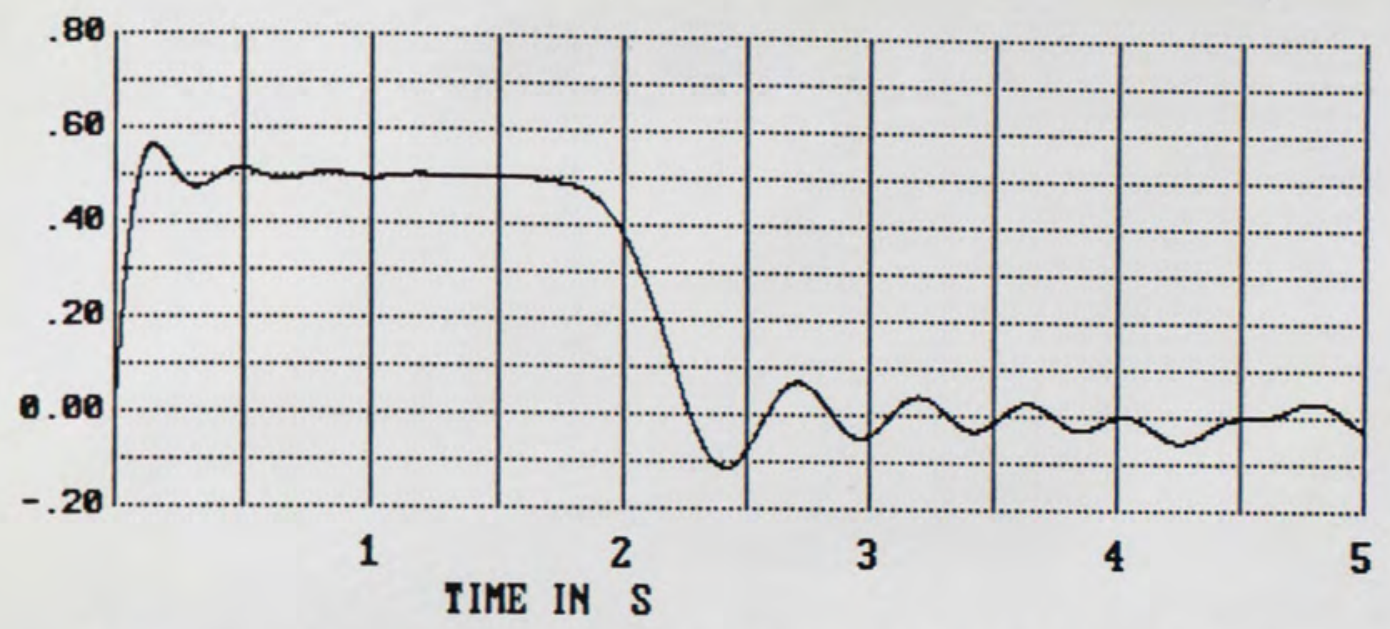

Figure 16. Output Pulse Shape for a 9-Mesh PFN.

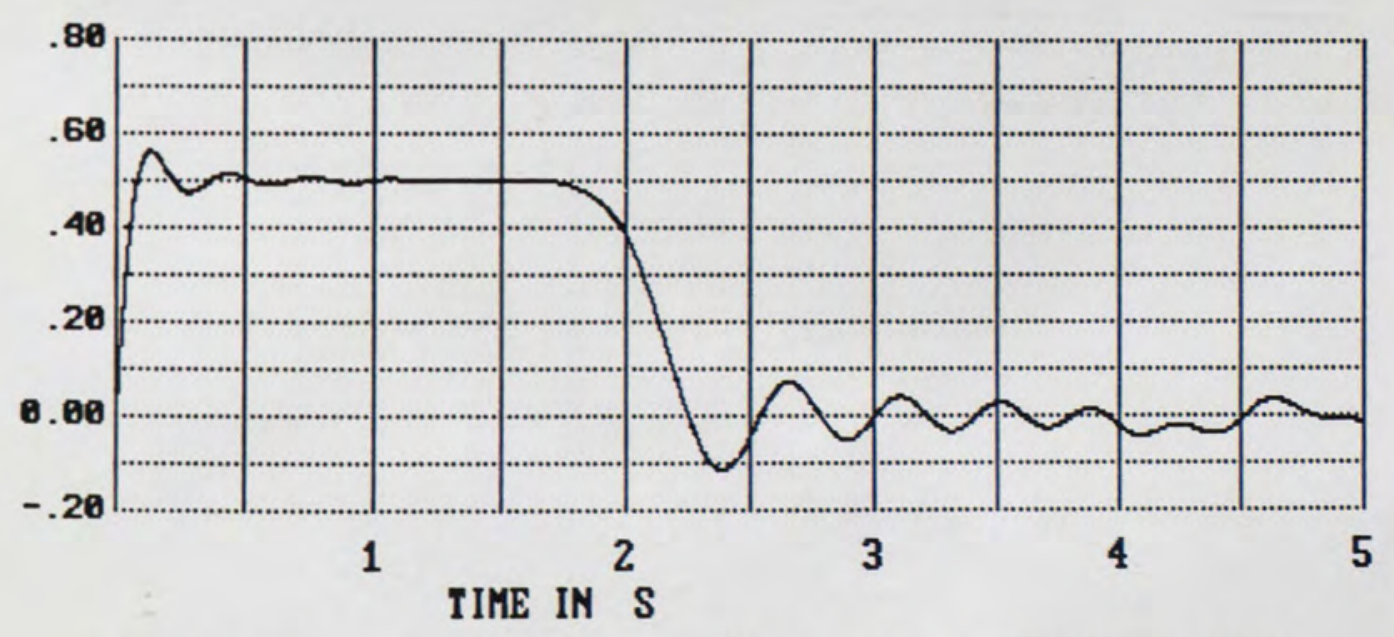

Figure 17. Output Pulse Shape for a 10-Mesh PFN. 
From the transmission line analogy the output pulse width was $T=2 X(L C)^{1 / 2}$. From these simulations, the $X$ which was the length of transmission line now becomes the number of meshes in the network. This pulse width will fall somewhere between the $50 \%$ to $70 \%$ points. The rise time from the $10 \%$ to $80 \%$ points turn out to be $t_{r}=T / 2 n$, where $\mathrm{n}$ is the number of meshes (Koechner 1976, 293).

Notice that the overshoot is approximately $10 \%$ in every case, but its duration decreases with the increase in the number of meshes. This is important in that the amount of energy in that overshoot decreases, and therefore the stored energy is more uniformly distributed throughout the pulse duration.

\section{A 20-Mesh Simulation And Fourier Analysis}

For this simulation a switch was added between the PFN and load in order to delay the output pulse to be in the center of the transient analysis' time window. This delay will allow approximately equal time before and after the pulse where the output is zero. This output simulation will then be analyzed by using the Fourier analysis portion of Microcap II.

The ladder network is composed of 20 capacitors where $\mathrm{C}=0.1$ and 20 inductors where $\mathrm{L}=0.1$. The pulse width will then be $\mathrm{T}=2(20)(0.1 * 0.1)^{1 / 2}=4$ seconds. 
The resulting pulse is shown in Figure 18. Even for the 20-mesh PFN there is still a $10 \%$ overshoot, but the pulse is remarkably flat and rectangular.

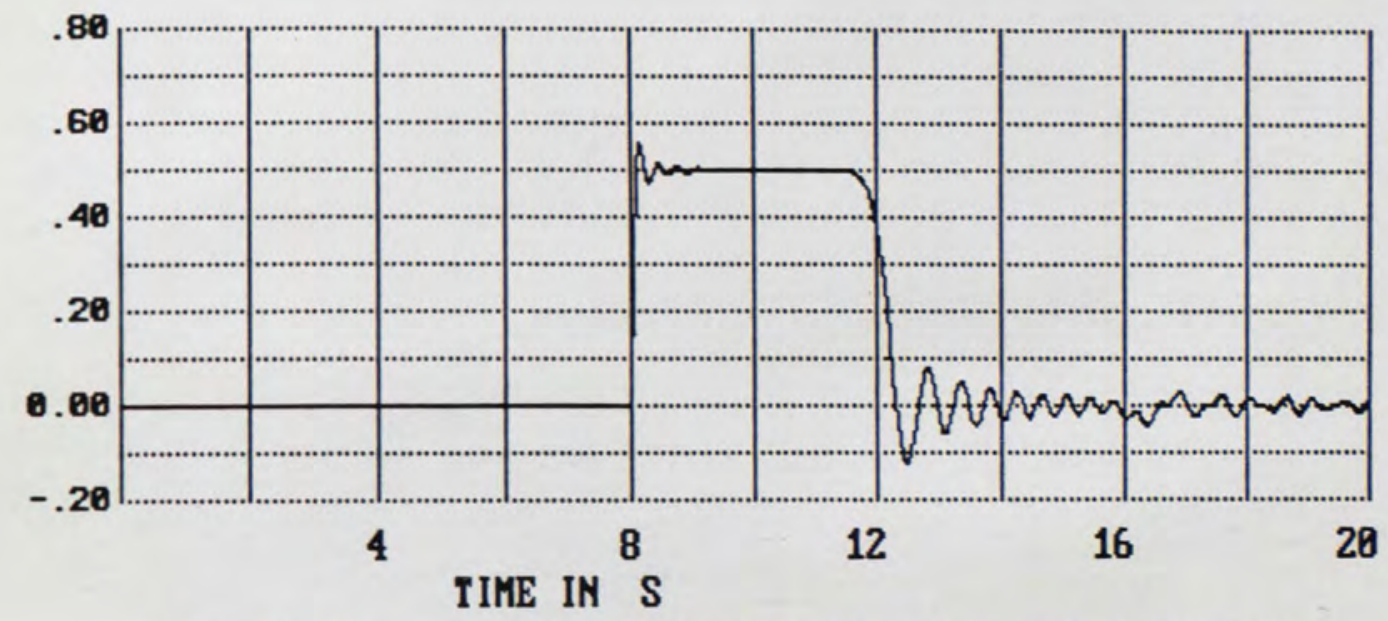

Figure 18. Output Pulse Shape of a 20-Mesh PFN Delayed 8 seconds.

The Fourier analysis of the pulse is displayed in Figure 19. The magnitude plot has the familiar $\sin x / x$ function shape. The pulse is made up almost entirely of cosine components, and the sine component contribution is barely noticeable. This simulation shows that approximating a charged transmission line with a lumped constant ladder network can be accomplished very effectively. 


\section{Haveform}
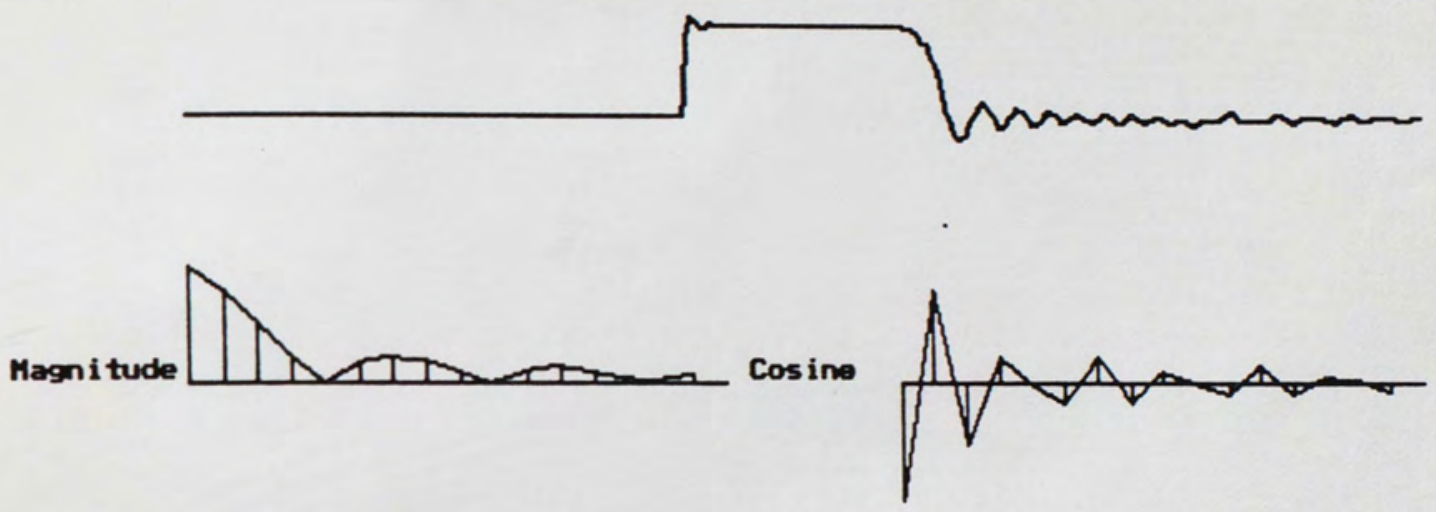

Angle

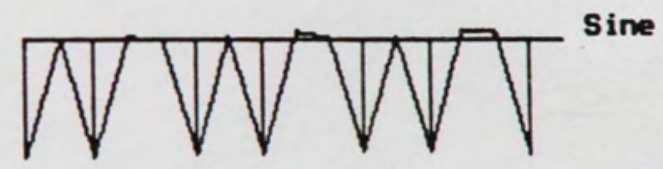

Figure 19. Fourier Analysis for the Output Pulse of the 20-Mesh PFN. 


\section{DESIGN PARAMETERS}

Now that it has been shown that a rectangular pulse is obtained from an equal inductor and capacitor ladder network, design guide equations will be generated so that component values can be calculated for a real PFN. Then, the performance of an actual circuit will be compared to the simulations for that PFN.

\section{Design Intangibles}

For the manufacturers of equipment that use multiplemesh PFNs, the equal LC network works in their favor. Since the inductors are of the same value, only one part needs to be stocked, and the same goes for the capacitors. This lowers the inventory cost and reduces the chance of production errors.

In many cases the capacitors and inductors that are used are not typical off-the-shelf items, and need to be custom made. If custom-made parts are required, it is advantageous to be able to order as large a quantity as possible to get the best price breaks. For example, it may be less expensive to design a multi-mesh PFN that uses eight inductors and capacitors instead of a design that uses four! 
These economies of scale unfortunately cannot be included in the component value equations, but need to be taken into account by the designer. For this reason the designer needs good contact with the capacitor and inductor manufacturers for help in the design process.

\section{Flashlamp Characteristics}

Early on in the report it was stated that pulse forming networks generally drive non-linear loads. These load parameters must be known before component values can be calculated. Since this report is concerned with extended pulse widths for laser welders, the non-linear load considered will be a gas filled flashlamp typically used in solid state lasers.

A flashlamp's instantaneous voltage and current is a function of its dynamic impedance $k_{0}$ that has units of ohms-amps $1 / 2$. The lamp's voltage can then be written as:

$$
v= \pm K_{0}|i|^{1 / 2} \text {, volts }
$$

(EG\&G Electro-Optics 1983, 7).

The impedance $K_{0}$ has been shown to be related to the type of gas, the gas pressure, and the lamp's physical size by:

$$
K_{0}=\frac{1.28}{d} * 1(p / x)^{1 / 5}, \text { ohms-amps } s^{1 / 2}
$$

where 1 is the arc length in $\mathrm{mm}$, $\mathrm{d}$ is the bore diameter in $\mathrm{mm}, \mathrm{p}$ is the fill pressure in torr, and $\mathrm{x}$ is a gas 
constant (EG\&G Electro-Optics 1983, 7). For solid state lasers either xenon $(x=450)$ or krypton $(x=805)$ is generally used.

Flashlamps also have a negative impedance region which must be overcome if any of this is to work. The manuals and application notes from the flashlamp manufacturers explain the different triggering schemes. Triggering requires a high voltage pulse in the order of 10 to 20 thousand volts and requires a single-mesh PFN of its own.

These manuals also explain the advantages of "simmering" a flashlamp, which keeps the lamp in an ionized condition so that triggering is not necessary for every pulse. Some of the most important advantages a simmered lamp offers is higher laser pumping efficiency, increased lamp life, and higher repetition rates (ILC Technology 1983). Industrial pulsed lasers keep the lamps simmered for these reasons, but military lasers may not simmer the lamps since this consumes extra power and requires more cooling.

\section{PFN Component Calculations}

The single-mesh PFN component value computations will be considered first, and then those for multi-mesh networks. The values for these will differ since the goal 
is to have the single-mesh critically damped and the multi-mesh impedance matched.

\section{Single-Mesh Circuit Values}

The solution to the single-mesh circuit driving a non-linear load flashlamp was studied by Markiewicz and Emmett. They reported their findings in the IEEE Journal of Quantum Electronics in 1966. The solution for a given flashlamp with impedance factor $k_{0}$, pulse width $t$, and stored energy $\mathrm{E}_{\mathrm{o}}$ turns out to yield only one value of capacitance and inductance for critical damping. Those component values are calculated as follows:

$$
\begin{aligned}
& \mathrm{C}=\left(2 \mathrm{E}_{\mathrm{O}} \alpha^{4} \mathrm{~T}^{2} \mathrm{~K}_{\mathrm{O}}^{-4}\right)^{1 / 3} \text { farads } \\
& \mathrm{L}=\mathrm{T}^{2} / \mathrm{C} \text { henries } \\
& \mathrm{V}_{\mathrm{O}}=\left(2 \mathrm{E}_{\mathrm{O}} / \mathrm{C}\right)^{1 / 2} \text { capacitor charge voltage }
\end{aligned}
$$

where:

$\mathrm{E}_{\mathrm{O}}=$ stored energy in joules $\alpha=\mathrm{K}_{\mathrm{O}} /\left(\mathrm{V}_{\mathrm{O}} \mathrm{z}_{\mathrm{o}}\right)^{1 / 2}$ a damping factor and equal to 0.8 for critical damping, $>0.8$ for underdamping $\mathrm{z}_{\mathrm{O}}=(\mathrm{L} / \mathrm{C})^{1 / 2}$ ohms $\mathrm{K}_{\mathrm{o}}=\mathrm{flashlamp}$ impedance factor in ohms-amps ${ }^{1 / 2}$ $\mathrm{T}=\mathrm{t} / 3$ circuit time constant approximation in seconds $t=$ pulse width in seconds (Markiewicz and Emmett 1966, as cited in EG\&G Electro-Optics 1983, 8-9). 
These equations work well for the design of the single-mesh PFN. The approximation for $T$ is actually closer to $t / 2.5$ for the critically damped case, as was shown earlier in this report from equation (13). As the circuit becomes underdamped, the pulse width spreads and $T$ becomes closer to $t / 3$ (EG\&G Electro-optics 1983, A-3).

In many cases the PFN must operate over a stored energy range. Since there is only one operating point that is critically damped, that operating point needs careful consideration. From experience the designer normally would pick the maximum stored energy level for the critically damped case, since this is the point where the lamp impedance is at its lowest.

Then for the lower stored energy operation the circuit becomes underdamped. This is advantageous because there is no current reversal for underdamped cases. As mentioned earlier, current reversal can lead to early lamp failure and circuit component damage (ILC Technology 1983) .

\section{Multi-Mesh Circuit Values}

The report has shown that for a uniform energy discharge a ladder LC network composed of equal value capacitors and inductors approximates a transmission line that generates a rectangular output pulse when terminated in a matched load impedance. Now one needs to know how to 
calculate the values for those capacitors and inductors to achieve a working circuit. The approach of critical damping does not apply in this case, but the matched termination to the transmission line is what is desired.

To begin with, since the energy stored is to be dumped into the lamp in an approximate rectangular pulse, it can be written:

$$
\mathrm{E}_{\mathrm{o}}=\mathrm{nCV}_{0}^{2} / 2=\mathrm{v}_{1} \mathrm{I}_{1} \mathrm{~T} \text { joules }
$$

where $\mathrm{n}$ is the number of meshes, $\mathrm{C}$ is the capacitance per mesh, $v_{0}$ is the initial charge voltage, $V_{1}$ and $I_{1}$ are the pulsed lamp voltage and current, respectively, and $T$ is the pulse width.

From the relationship of the lamp voltage to current, the energy equation can be rewritten as:

$$
E_{0}=T K_{0}\left(I_{l}\right)^{3 / 2} \text { joules. }
$$

Solving for the lamp current yields:

$$
I_{1}=\left(E_{0} / K_{O} T\right)^{2 / 3} \text { amps. }
$$

The network impedance $z_{0}$ is defined as $z_{0}=(L / C)^{1 / 2}$ ohms, and the lamp impedance during the pulse is $R_{1}=V_{1} / I_{1}$ ohms. Using the lamp impedance factor $\mathrm{K}_{0}$, the lamp impedance is then $R_{1}=K_{o} / I_{1}{ }^{1 / 2}$. Remembering that the pulse width $\mathrm{T}=2 \mathrm{n}(\mathrm{LC})^{1 / 2}$, and impedance matching $\mathrm{R}_{1}=\mathrm{Z}_{0}$, then 
solving for $\mathrm{C}$ will yield:

$$
\mathrm{C}=\mathrm{TI}_{1} 1 / 2 / 2 \mathrm{nK}_{0} \text { farads. }
$$

Substituting $I_{1}$ from equation (36) above into equation (37) will result in:

$$
C=\left(E_{0} T^{2} / K_{0}{ }^{4}\right)^{1 / 3} / 2 n \text { farads. }
$$

Now knowing the desired stored energy $\mathrm{E}_{O}$, the pulse width $\mathrm{T}$, the flashlamp impedance factor $\mathrm{K}_{\mathrm{O}}$, and the number of meshes $\mathrm{n}$, one can calculate the capacitor's value.

The capacitor's initial charge voltage will be

$$
v_{0}=\left(2 E_{0} / n C\right)^{1 / 2} \text { volts. }
$$

The inductor value can then be calculated from the pulse width T giving:

$$
\mathrm{L}=\mathrm{T}^{2} / 4 \mathrm{n}^{2} \mathrm{C} \text { henries. }
$$

Substituting in the result for the capacitor will then yield:

$$
\mathrm{L}=\left(\mathrm{T}^{4} \mathrm{~K}_{\mathrm{O}}^{4} / \mathrm{E}_{\mathrm{O}}\right)^{1 / 3} / 2 \mathrm{n} \text { henries. }
$$

These equations are similar to the equations listed in the ILC Technology Technical Bulletin 2, "A Guide to Flashlamps for Pulsed Solid State Lasers" from 1983, but there the result is the total capacitance and inductance of the network, not the individual component values. 
If a desired pulse rise time is required, then the number of meshes can be calculated from the equation $t_{r}=T / 2 n$ which is the $10 \%$ to $80 \%$ points. Care must be taken if a very fast rise time is required, since lamp wall damage can occur very quickly for a rate of rise of current that exceeds $100 \mathrm{~A} / \mu \mathrm{s}$ (ILC Technology 1983). Lamps operated in the 100 joule level at rise times of $50 \mu \mathrm{s}$ and lamps operated in the kilojoule levels at $200 \mu \mathrm{s}$ rise times have been found to suffer severe electrode sputtering and wall crazing (Koechner 1976, 293).

These equations for matching the lamp impedance to the network impedance look good, but there is a problem with them. The simulations from Microcap II for the various mesh circuits show undershoot ringing in every case, and this ringing or current reversal has been pointed out to be detrimental to the flashlamp.

Due to this problem it has been found empirically that if the load is mismatched slightly by $1.3 \mathrm{z}_{0}$ that the negative undershoot will now be just above the zero point. This means that no current reversal takes place, and the mismatch may also help in commutating the switch if it is an SCR since the current in the last inductor will be close to zero. This also keeps the capacitors from experiencing voltage reversal, which decreases a capacitor's life. 
Then substituting this mismatch factor into the capacitor and inductor equations yields:

$$
\begin{aligned}
& \mathrm{C}=1.3\left(\mathrm{E}_{\mathrm{O}} \mathrm{T}^{2} / \mathrm{K}_{\mathrm{O}}{ }^{4}\right)^{1 / 3} / 2 \mathrm{n} \text { farads } \\
& \mathrm{L}=\left(\mathrm{T}^{4} \mathrm{~K}_{\mathrm{O}}{ }^{4} / \mathrm{E}_{\mathrm{O}}\right)^{1 / 3} /(1.3 * 2 \mathrm{n}) \text { henries. }
\end{aligned}
$$

If the PFN is supposed to operate over a range of stored energies, then these component values should be computed for the maximum energy operating point just like the single-mesh case. In this manner the mismatch actually is greater than the 1.3 factor for the lower energy levels, but this will still insure that no current reversal takes place. 


\section{PFN DESIGN EXAMPLE}

Now that the design equations have been developed they can be applied to a pulsed laser that is used for drilling and welding. The present configuration of the laser's PFN will be compared to the new configuration that follows the design parameters.

To begin with, the laser used is made by Control Laser Corporation in orlando, Florida for drilling, cutting, and welding a variety of metals. A picture showing the pulse forming network inside its enclosure is shown in Figure 20. The capacitors and inductors are large components that are wired for high current pulses. The inductors for high energy discharge are usually air core types, and the capacitors are generally of oil filled paper dielectric construction.

This laser has three different pulse widths that are made possible by isolating the different meshes in the network with high current diodes (see Figure 21). By charging just the first capacitor, the first pulse width is achieved. The second pulse width is accomplished by charging two of the capacitors, while the third uses all of the capacitors. 




Figure 20. PFN Construction of an Industrial Laser. 


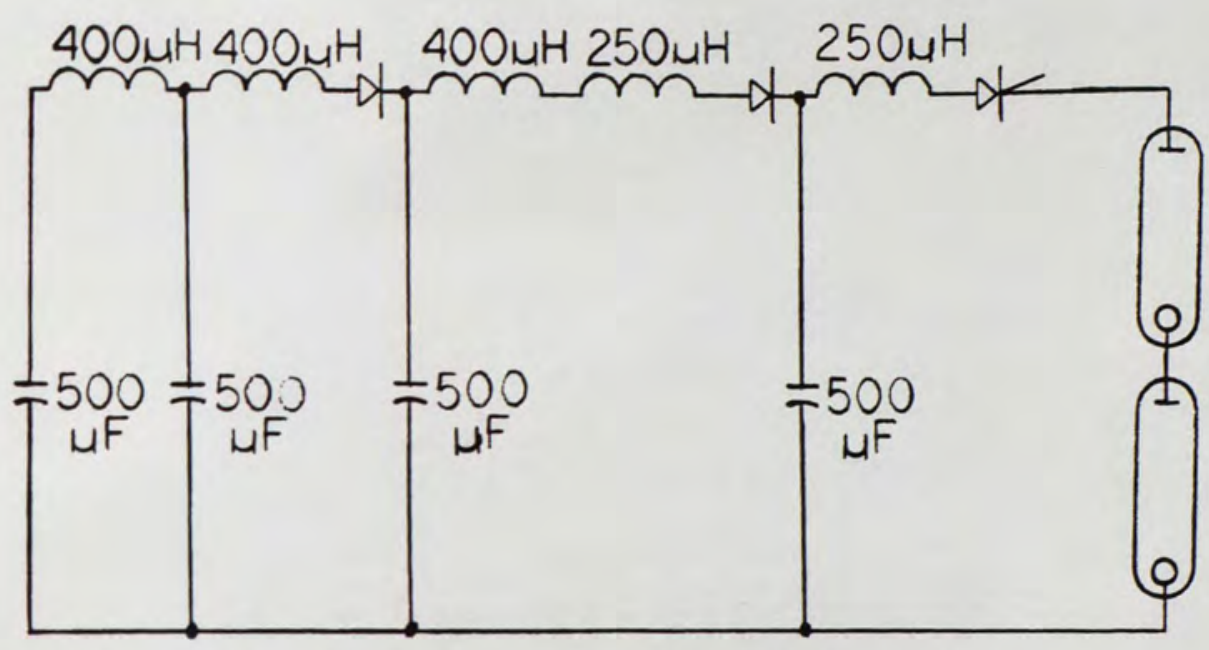

Figure 21. PFN Circuit of an Industrial Laser.

The largest use of this laser is for drilling holes in jet engine turbine blades. It is not used often for welding due to its third pulse shape that tends to vaporize the material instead of just melting it.

As mentioned earlier a flashlamp is a nonlinear load; therefore, an approximation to the flashlamp was accurately achieved by using a polynomial current source as the load. The current source's parameters were defined as $I=V^{2} / K_{0}{ }^{2}$ from the flashlamp equation (29). The simulation for the laser's third pulse width discharge current and power is shown in Figure 22.

The actual performance is shown in Figures 23 and 24 , and was accurately predicted by the simulation. In Figure 23 the discharge current is shown. The laser's optical output pulse (shown in Figure 24) is directly proportional to the discharge's instantaneous power. This pulse is far 
from having a uniform discharge. Since the instantaneous power is proportional to $\mathrm{I}^{3 / 2}$, any fluctuations in the current are worse in the power output.
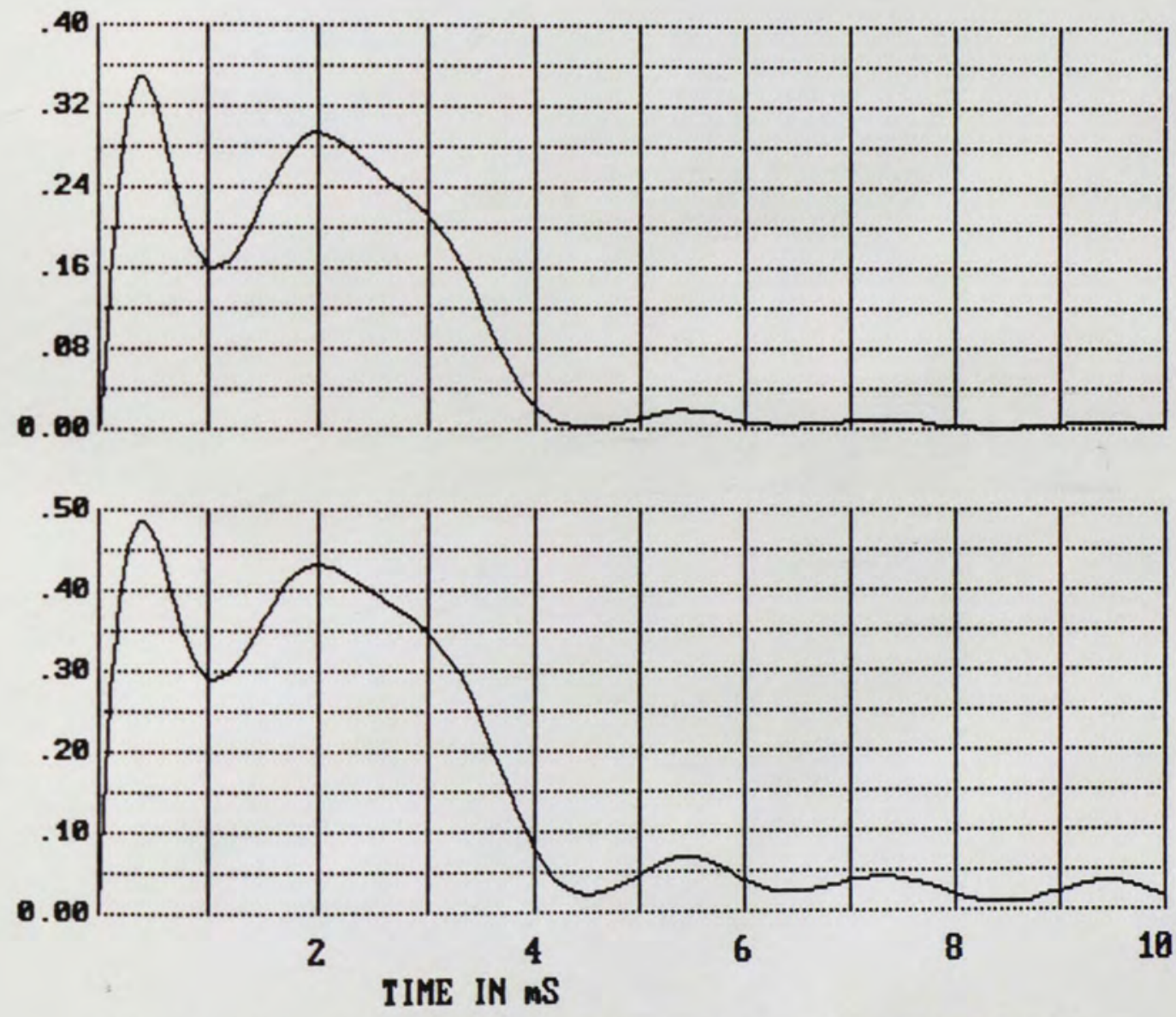

Figure 22. Present PFN Configuration Discharge Current and Power Simulation Top Trace output Power (MW) Bottom Trace Output Current (kA). 


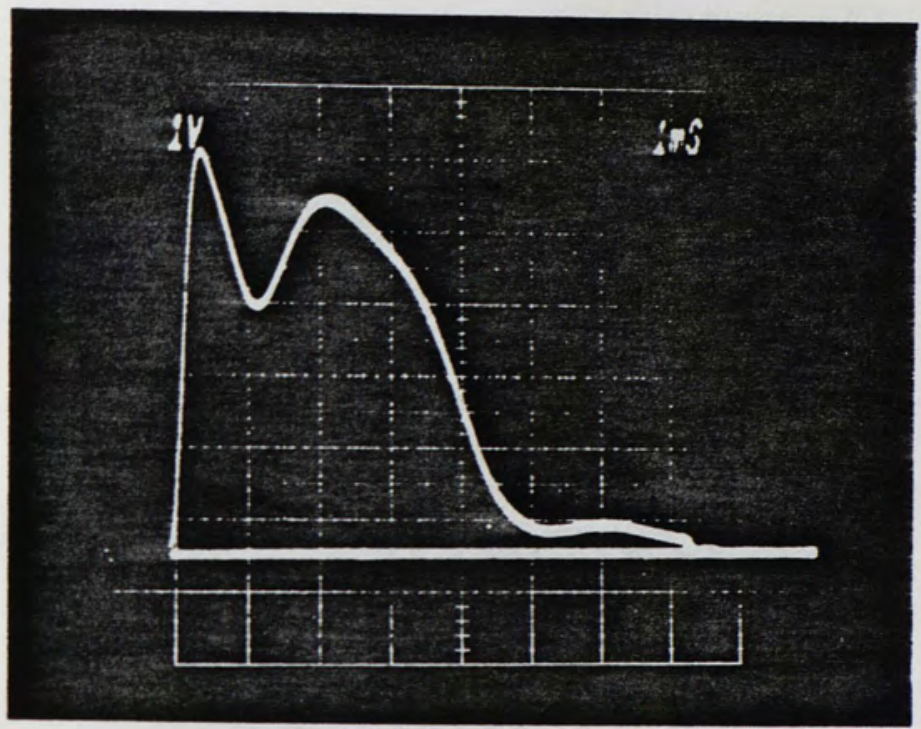

Figure 23. Discharge Current Into the Flashlamps. 100 Amps/div. $1 \mathrm{msec} /$ div.

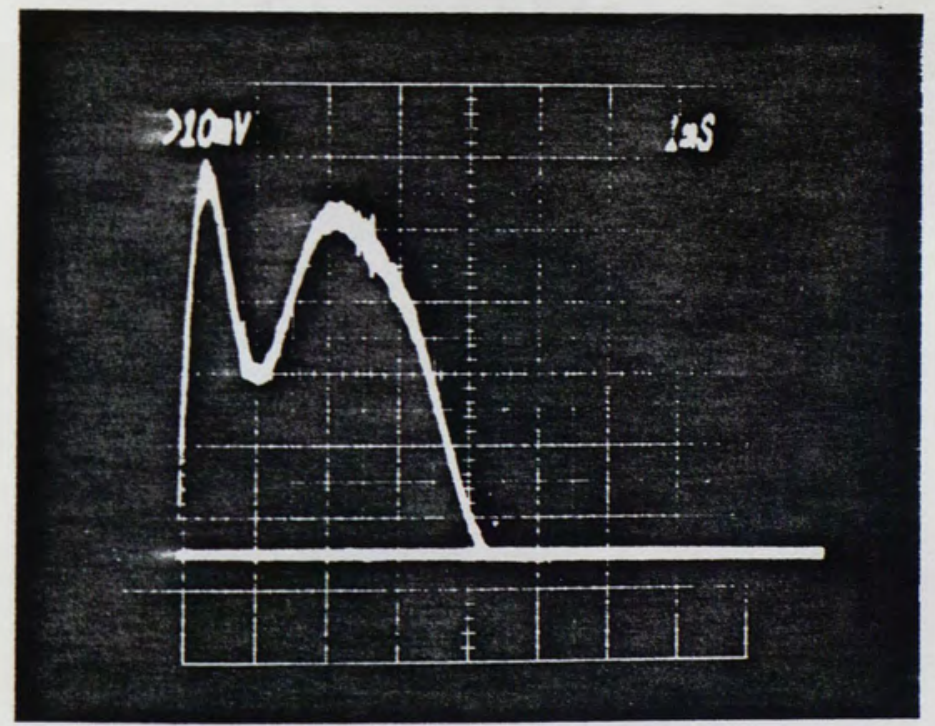

Figure 24. Resulting Laser optical Output Pulse. 
Applying the design criteria specified earlier, it is desired to have the same pulse width and energy, but a uniform discharge. From Figure 23 the pulse width is measured to be approximately $3.5 \mathrm{milliseconds}$ at the $60 \%$ points. The maximum energy is selected to be 2500 joules, delivered into two flashlamps in series with $\mathrm{K}_{0}=16.3$ ohms$\operatorname{amps}^{1 / 2}$ each. The mesh number is four.

Since there are two flashlamps, the combined impedance factor will be $2 \mathrm{~K}_{\mathrm{o}}=32.6 \mathrm{ohms}^{-\mathrm{amps}^{1 / 2}}{ }^{1 /}$ Now substituting into equation (42) for the capacitance $C=1.3 *\left(2500 * 0.0035^{2} / 32.6^{4}\right)^{1 / 3} / 2 * 4=488$ microfarads, and then solving for the inductance from equation (40) yields:

$\mathrm{L}=0.0035^{2} /\left(4 * 4^{2} * 488 \times 10^{-6}\right)=392$ microhenries.

The maximum voltage needed for this application is then:

$\mathrm{v}_{\mathrm{i}}=\left(2 * 2500 /\left(4 * 488 \times 10^{-6}\right)^{1 / 2}=1600\right.$ volts.

The actual values of the capacitors were measured and found to be between $441 \mathrm{uF}$ and $465 \mathrm{uF}$, which is within a $10 \%$ tolerance. The inductor values were from $324 \mathrm{uH}$ to $329 \mathrm{uH}$, which is within a $20 \%$ tolerance. Figure 25 shows a simulation for this PFN using an average capacitor value of $450 \mathrm{uF}$ and $330 \mathrm{uH}$ for the inductors with an initial voltage of 1000 volts. The upper trace is the load power, and the lower trace is the load current. 
Figure 26 indicates the current that was achieved from this PFN when charged to 1000 volts. The trace of the laser's optical pulse is in Figure 27. These two pictures show the similarity to the simulation and how nicely the energy discharge becomes uniform with the equal capacitor and inductor design.
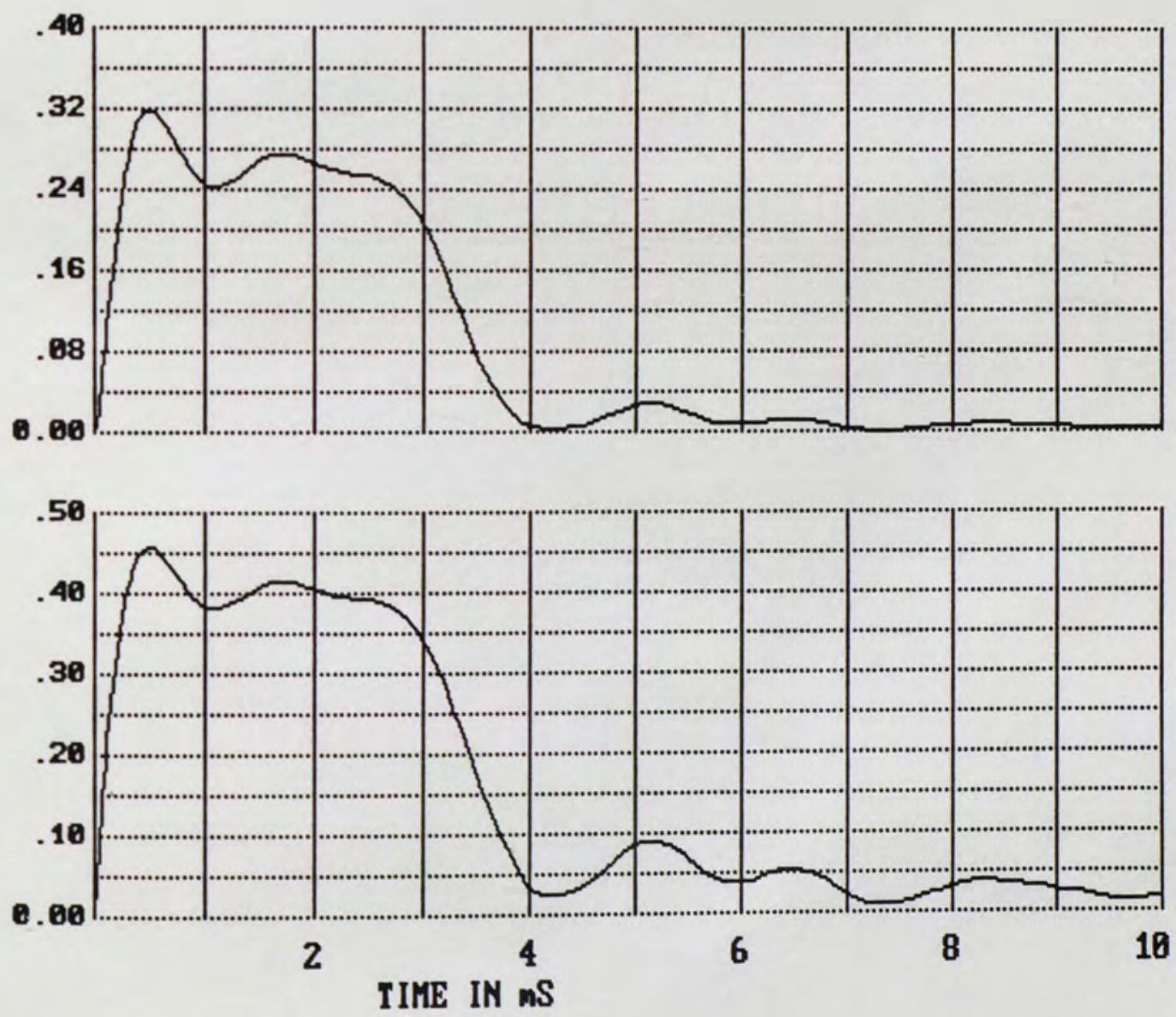

Figure 25. Simulation Results for the New PFN Top Trace Output Power (MW), Bottom Trace output current (kA). 


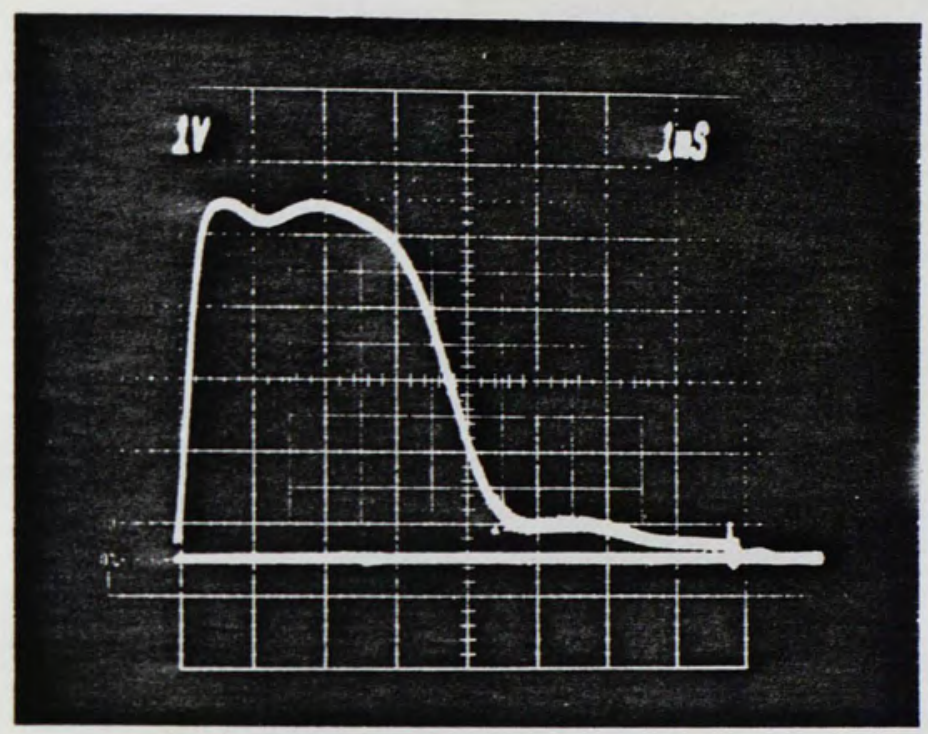

Figure 26. The New PFN Design Output Current Pulse.

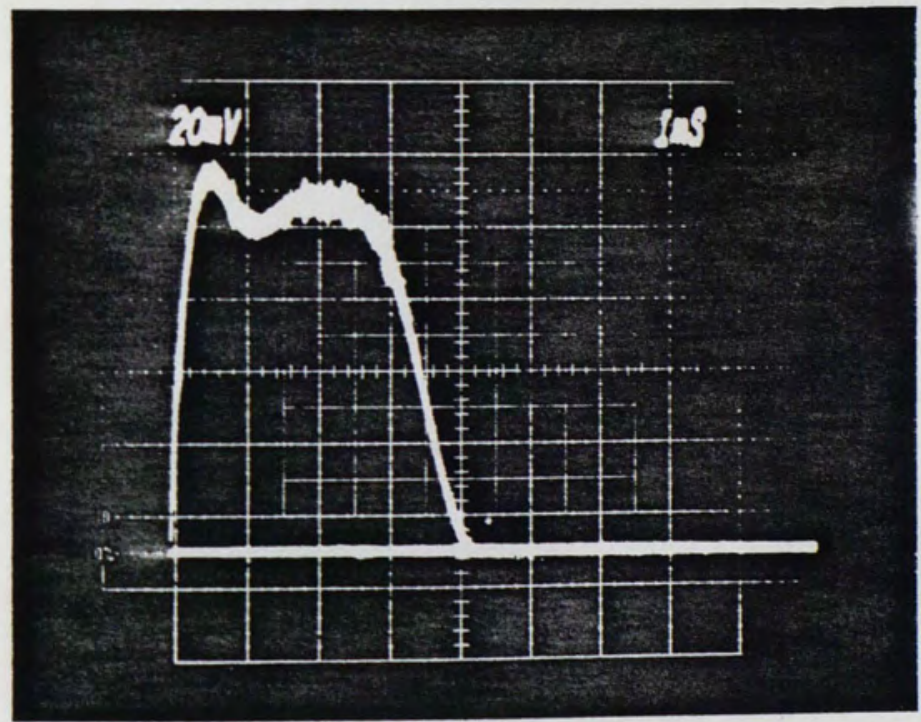

Figure 27. The New PFN Design Output Optical Pulse. 


\section{CONCLUDING REMARKS}

A pulse forming network can achieve a rectangular output pulse when the design incorporates equal value capacitors and inductors. The ladder network that results evenly distributes the stored energy among the capacitors, and with the inductors forms a lumped constant transmission line approximation which yields the desired output pulse. The resultant rectangular pulse is highly desirable since it provides a uniform energy distribution within the pulse for improved material processes such as laser welding. 
APPENDIX 


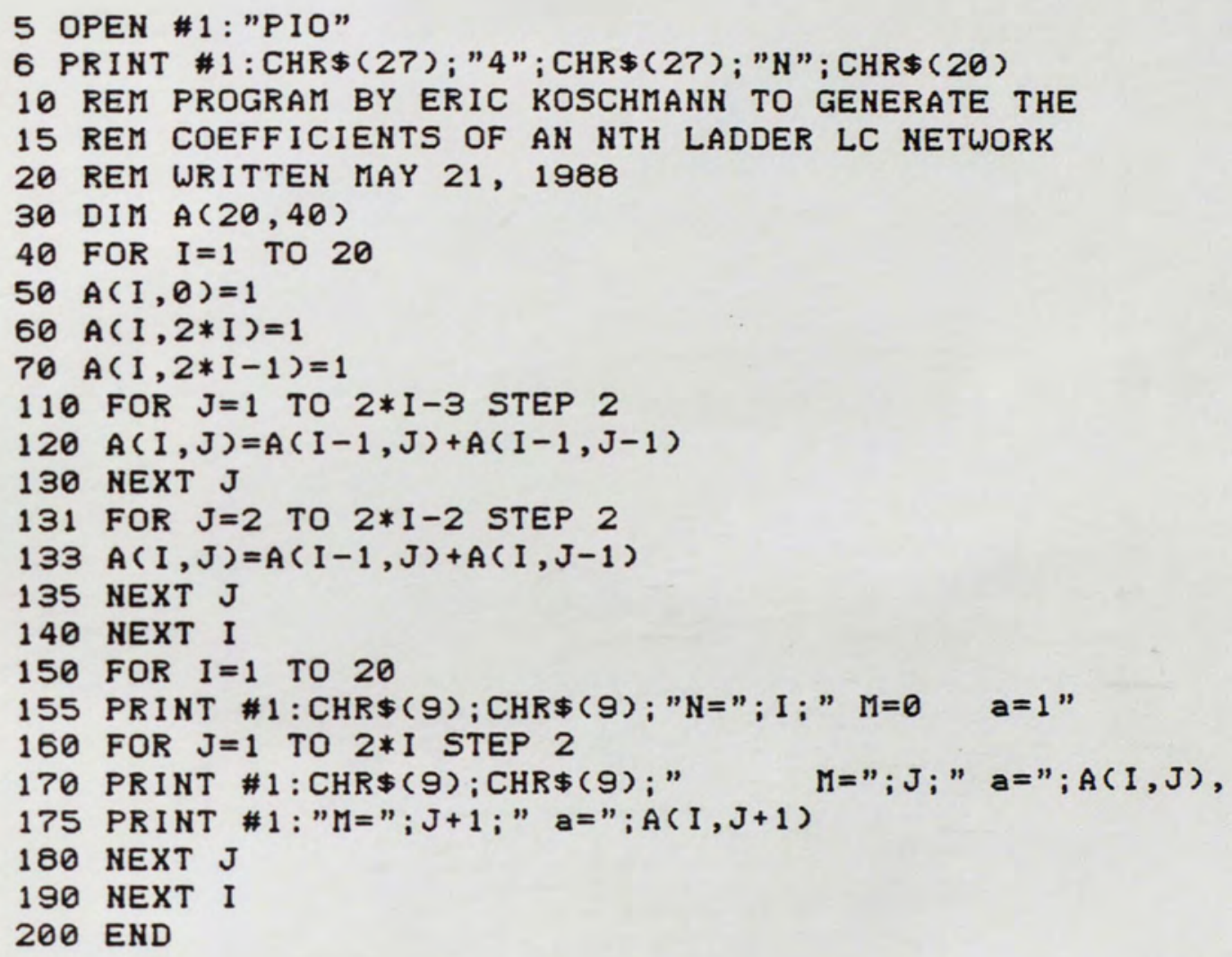




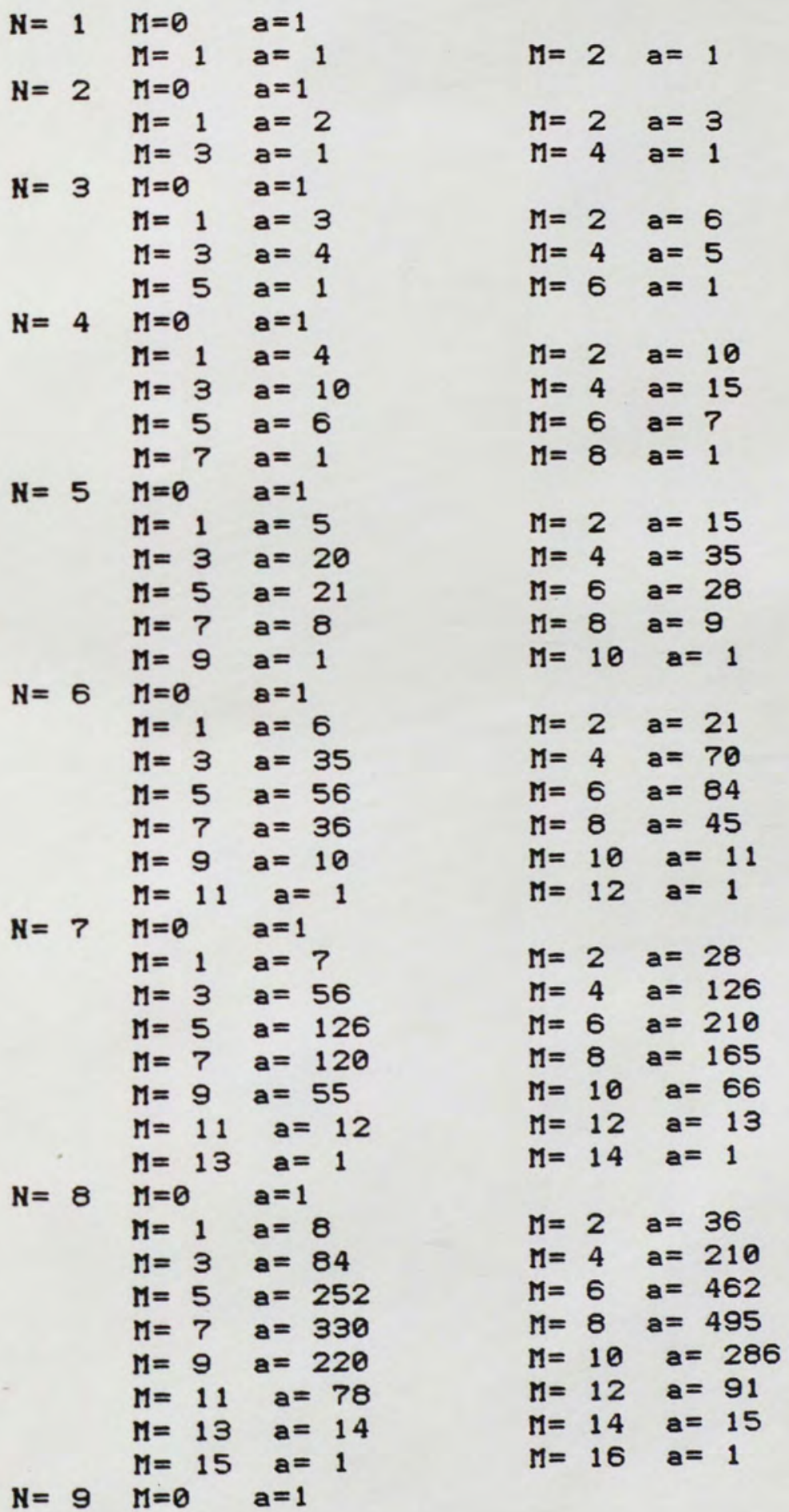




\begin{tabular}{|c|c|c|c|c|c|}
\hline & $M=1$ & $a=9$ & $M=$ & 2 & $a=45$ \\
\hline & $M=3$ & $a=120$ & $M=$ & 4 & $a=330$ \\
\hline & $M=5$ & $a=462$ & $M=$ & 6 & $a=924$ \\
\hline & $M=?$ & $a=792$ & $M=$ & 8 & $a=1287$ \\
\hline & $M=9$ & $a=715$ & $M=$ & 10 & $a=1001$ \\
\hline & $M=11$ & $a=364$ & $M=$ & 12 & $a=455$ \\
\hline & $M=13$ & $a=105$ & $M=$ & 14 & $a=120$ \\
\hline & $M=15$ & $a=16$ & $M=$ & 16 & $a=17$ \\
\hline & $M=17$ & $a=1$ & $M=$ & 18 & $a=1$ \\
\hline$=10$ & $M=0$ & $a=1$ & & & \\
\hline & $M=1$ & $a=10$ & $M=$ & 2 & $a=55$ \\
\hline & $M=3$ & $a=165$ & $M=$ & 4 & $a=495$ \\
\hline & $M=5$ & $a=792$ & $M=$ & 6 & $a=1716$ \\
\hline & $M=7$ & $a=1716$ & $M=$ & 8 & $a=3003$ \\
\hline & $M=9$ & $a=2002$ & $M=$ & 10 & $a=3003$ \\
\hline & $M=11$ & $a=1365$ & $M=$ & 12 & $a=1820$ \\
\hline & $M=13$ & $a=560$ & $M=$ & 14 & $a=680$ \\
\hline & $M=15$ & $a=136$ & $M=$ & 16 & $a=153$ \\
\hline & $M=17$ & $a=18$ & $M=$ & 18 & $a=19$ \\
\hline & $M=19$ & $a=1$ & $M=$ & 20 & $a=1$ \\
\hline 11 & $M=0$ & $a=1$ & & & \\
\hline & $M=1$ & $a=11$ & $M=$ & 2 & $a=66$ \\
\hline & $M=3$ & $a=220$ & $M=$ & 4 & $a=715$ \\
\hline & $M=5$ & $a=1287$ & $M=$ & 6 & $a=3003$ \\
\hline & $M=7$ & $a=3432$ & $M=$ & 8 & $a=6435$ \\
\hline & $M=9$ & $a=5005$ & $M=$ & 10 & $a=8008$ \\
\hline & $M=11$ & $a=4368$ & $M=$ & 12 & $a=6188$ \\
\hline & $M=13$ & $a=2380$ & $M=$ & 14 & $a=3060$ \\
\hline & $M=15$ & $a=816$ & $M=$ & 16 & $a=969$ \\
\hline & $M=17$ & $a=171$ & $M=$ & 18 & $a=190$ \\
\hline & $M=19$ & $a=20$ & $M=$ & 20 & $a=21$ \\
\hline & $M=21$ & $a=1$ & $M=$ & 22 & $a=1$ \\
\hline $\mathrm{N}=12$ & $M=0$ & $a=1$ & & & \\
\hline & $M=1$ & $a=12$ & $M=$ & 2 & $a=78$ \\
\hline & $M=3$ & $a=286$ & $M=$ & 4 & $a=1001$ \\
\hline . & $M=5$ & $a=2002$ & $M=$ & 6 & $a=5005$ \\
\hline & $M=7$ & $a=6435$ & $M=$ & 8 & $a=12870$ \\
\hline & $M=9$ & $a=11440$ & $M=$ & 10 & $a=19448$ \\
\hline & $M=11$ & $a=12376$ & $M=$ & 12 & $a=18564$ \\
\hline & $M=13$ & $a=8568$ & $M=$ & 14 & $a=11628$ \\
\hline & $M=15$ & $a=3876$ & $M=$ & 16 & $a=4845$ \\
\hline & $M=17$ & $a=1140$ & $M=$ & 18 & $a=1330$ \\
\hline & $M=19$ & $a=210$ & $M=$ & 20 & $a=231$ \\
\hline & $M=21$ & $a=22$ & $M=$ & 22 & $a=23$ \\
\hline & $M=23$ & $a=1$ & $M=$ & 24 & $a=1$ \\
\hline$=13$ & $M=0$ & $a=1$ & & & \\
\hline
\end{tabular}




\begin{tabular}{|c|c|c|c|c|c|c|c|}
\hline & & $M=1$ & $a=13$ & $M=$ & 2 & $a=$ & 91 \\
\hline & & $M=3$ & $a=364$ & $M=$ & 4 & $a=$ & 1365 \\
\hline & & $M=5$ & $a=3003$ & $M=$ & 6 & $a=$ & 8008 \\
\hline & & $M=?$ & $a=11440$ & $M=$ & 8 & $a=$ & 24310 \\
\hline & & $M=9$ & $a=24310$ & $M=$ & 10 & $a=$ & $=43758$ \\
\hline & & $M=11$ & $a=31824$ & $M=$ & 12 & $a=$ & $=50388$ \\
\hline & & $M=13$ & $a=27132$ & $M=$ & 14 & $a=$ & $=38760$ \\
\hline & & $M=15$ & $a=15504$ & $M=$ & 16 & $a=$ & $=20349$ \\
\hline & & $M=17$ & $a=5985$ & $M=$ & 18 & $a=$ & $=7315$ \\
\hline & & $M=19$ & $a=1540$ & $M=$ & 20 & $a=$ & $=1771$ \\
\hline & & $M=21$ & $a=253$ & $M=$ & 22 & $a=$ & $=276$ \\
\hline & & $M=23$ & $a=24$ & $M=$ & 24 & $a=$ & $=25$ \\
\hline & & $M=25$ & $a=1$ & $M=$ & 26 & $a=$ & $=1$ \\
\hline & 14 & $M=0$ & $a=1$ & & & & \\
\hline & & $M=1$ & $a=14$ & $M=$ & 2 & $a=$ & 105 \\
\hline & & $M=3$ & $a=455$ & $M=$ & 4 & $a=$ & 1820 \\
\hline & & $M=5$ & $a=4368$ & $M=$ & 6 & $a=$ & 12376 \\
\hline & & $M=7$ & $a=19448$ & $M=$ & 8 & $a=$ & 43758 \\
\hline & & $M=9$ & $a=48620$ & $M=$ & 10 & $a=$ & $=92378$ \\
\hline & & $M=11$ & $a=75582$ & $M=$ & 12 & $a=$ & $=125970$ \\
\hline & & $M=13$ & $a=77520$ & $M=$ & 14 & $a=$ & $=116280$ \\
\hline & & $M=15$ & $a=54264$ & $M=$ & 16 & $a=$ & $=74613$ \\
\hline & & $M=17$ & $a=26334$ & $M=$ & 18 & $a=$ & $=33649$ \\
\hline & & $M=19$ & $a=8855$ & $M=$ & 20 & $a=$ & $=10626$ \\
\hline & & $M=21$ & $a=2024$ & $M=$ & 22 & $a=$ & $=2300$ \\
\hline & & $M=23$ & $a=300$ & $M=$ & 24 & $a=$ & $=325$ \\
\hline & & $M=25$ & $a=26$ & $M=$ & 26 & $a=$ & 27 \\
\hline & & $M=27$ & $a=1$ & $M=$ & 28 & $a=$ & $=1$ \\
\hline & 15 & $M=0$ & $a=1$ & & & & \\
\hline & & $M=1$ & $a=15$ & $M=$ & 2 & $a=$ & 120 \\
\hline & & $M=3$ & $a=560$ & $M=$ & 4 & $a=$ & 2380 \\
\hline & & $M=5$ & $a=6188$ & $M=$ & 6 & $a=$ & 18564 \\
\hline & & $M=?$ & $a=31824$ & $M=$ & 8 & $a=$ & 75582 \\
\hline & & $M=9$ & $a=92378$ & $M=$ & 10 & $a=$ & $=184756$ \\
\hline & & $M=11$ & $a=167960$ & $M=$ & 12 & $a=$ & $=293930$ \\
\hline & & $M=13$ & $a=203490$ & $M=$ & 14 & $a=$ & $=319770$ \\
\hline & & $M=15$ & $a=170544$ & $M=$ & 16 & $a=$ & $=245157$ \\
\hline & & $M=17$ & $a=100947$ & $M=$ & 18 & $a=$ & $=134596$ \\
\hline & & $M=19$ & $a=42504$ & $M=$ & 20 & $a=$ & $=53130$ \\
\hline & & $M=21$ & $a=12650$ & $M=$ & 22 & $a=$ & $=14950$ \\
\hline & & $M=23$ & $a=2600$ & $M=$ & 24 & $a=$ & $=2925$ \\
\hline & & $M=25$ & $a=351$ & $M=$ & 26 & $a=$ & $=378$ \\
\hline & & $M=27$ & $a=28$ & $M=$ & 28 & $a=$ & $=29$ \\
\hline & & $M=29$ & $a=1$ & $M=$ & 30 & $a=$ & $=1$ \\
\hline & 16 & $M=0$ & $a=1$ & & & & \\
\hline & & $M=1$ & $a=16$ & $M=$ & 2 & $a=$ & 136 \\
\hline
\end{tabular}




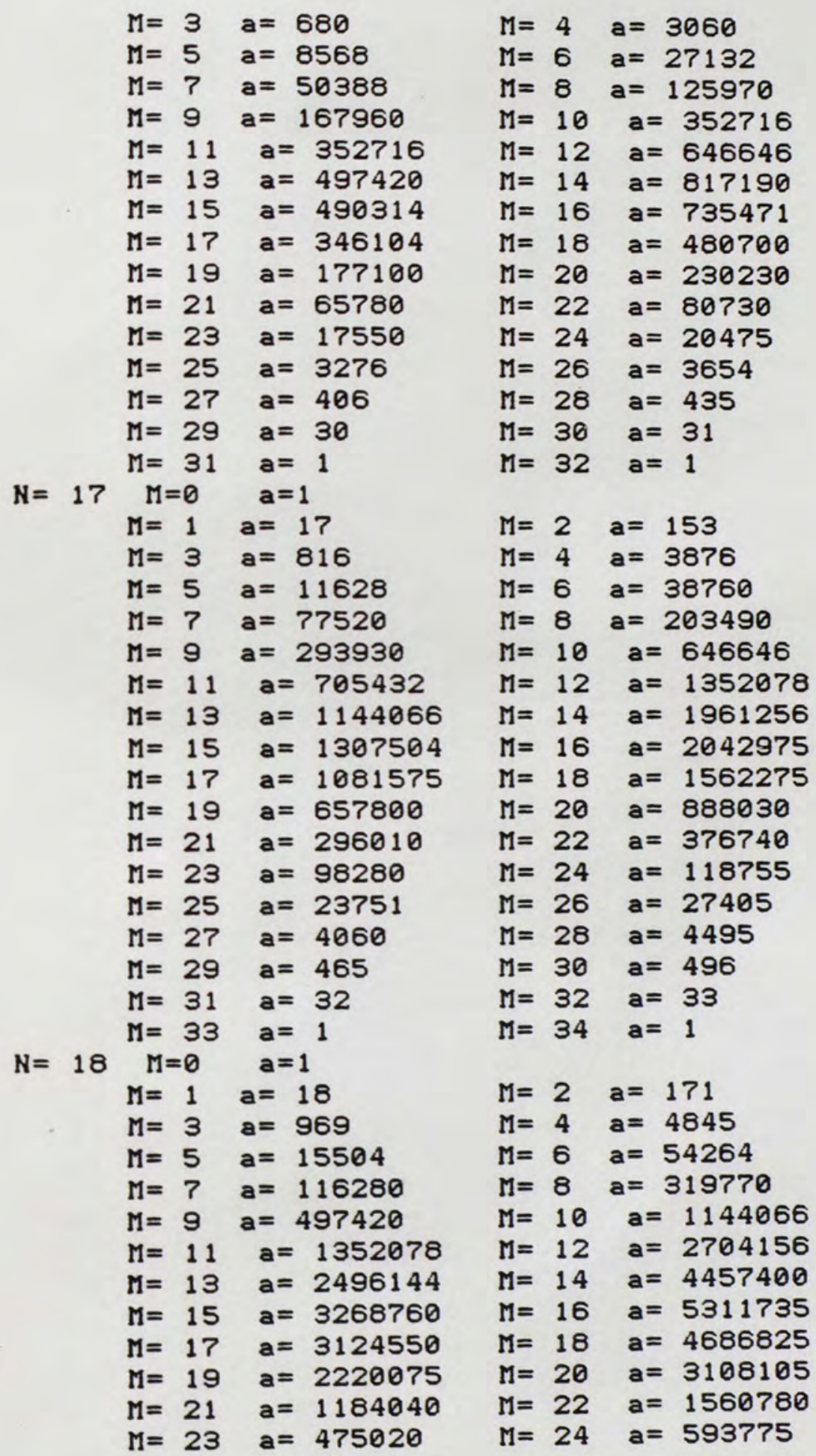









\section{REFERENCES}

Albrecht, A. P. 1977. Transmission Lines. In

Electronics Designers' Handbook. 2d ed. ed. L. J. Giacoletto, Section 8. New York: McGraw-Hill Book Company.

Barna, Arpad. 1970. High-Speed Pulse Circuits. New York: Wiley-Interscience.

Brown, Robert Grover, Robert A. Sharpe, William Lewis Hughes, and Robert E. Post. 1973. Lines, Waves, And Antennas The Transmission of Electric Energy. 2d ed. New York: John Wiley and Sons.

EG\&G Electro-optics. 1983. Flashlamp Applications Manual. Salem, Mass.: EG\&G Electro-optics.

ILC Technology. 1983. A Guide to Flashlamps for Pulsed Solid State Lasers Technical Bulletin 2. Sunnyvale Cal.: ILC Technology.

Koechner, w. 1976. Solid-State Laser Engineering. New York: Springer-Verlag. 